\title{
Second-best urban tolling with distributive concerns
}

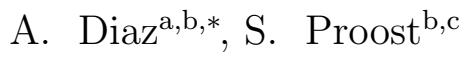 \\ ${ }^{a}$ IFP Energies Nouvelles, 1 et 4 Avenue de Bois-Preau, 92852 Rueil Malmaison Cedex, \\ France \\ ${ }^{b}$ Center of Economics Studies, KULeuven, Naamsestraat 69, 3000 Leuven, Belgium \\ ${ }^{c}$ Centre for Transport Studies, KTH, Stockholm, Sweden
}

\begin{abstract}
This paper analyzes the optimal urban congestion toll in a second-best setting where only one road in a network can be tolled. Both heterogeneity in labor productivity and income distribution concerns are considered. The optimal toll balances two types of considerations. The first consideration is the correction of the congestion externality on the tolled road given the distortion on the non-tolled roads, while the second is the equity consideration that takes into account which income group uses the tolled road and how toll revenues are spent. Both separating and pooling equilibriums are analyzed for two alternative uses of toll revenues: poll transfers and labor-tax cuts. Using numerical simulations, we show that equity concerns can lead a government to prefer inefficient toll levels and recycling via poll transfers rather than via labor tax reductions.
\end{abstract}

Keywords: Tax reform, congestion pricing, urban tolls

\section{Introduction}

Transport economists advocate road pricing as an efficient instrument to regulate the use of road infrastructures. Imposing a road toll that reflects marginal external congestion costs makes consumers use the road up to the

\footnotetext{
*Corresponding author

Email addresses: Andrea.DiazRincon@kuleuven.be (A. Diaz), Stef.Proost@econ.kuleuven.be (S. Proost)
} 
point where marginal social costs equalize marginal social benefits. Optimal road pricing therefore ensures that the only trips made are those that bring the highest benefits to society. This is only true, however, as long as tolling is analyzed in a first-best framework. Additional conditions, e.g. not being able to toll all roads in a network, pre-existing distortions on the labor market, or equity concerns complicate the optimal design of urban congestion tolls.

The related literature is mainly focused on the interaction of road taxes with taxes on labor income (see: Mayeres and Proost, 1997; Parry and Oates, 2000; Parry and Bento, 2001; Van Dender, 2003; Parry and Small, 2005; De Borger, 2009). The issue can be summarized as follows. Road taxes have a positive welfare impact by reducing congestion externalities. At the same time, however, they have a negative impact since an increase in commuting costs discourages labor supply. Which effect (externality reduction or reduced labor supply) prevails has become a central question in transport economics. Parry and Bento (2001) showed that the welfare impact of a road tax differs according to the use of the tax revenues. Using road tax revenues to reduce taxes on labor increases social welfare because reduced congestion and reduced labor taxes compensate workers for the congestion toll. Other revenue uses, such as poll transfers, do not compensate the negative labor supply impact and reduce welfare. On the other hand, Mayeres and Proost $(1997,2001)$ demonstrated that as long as equity objectives are relevant, obtaining significant welfare gains from recycling tax revenues requires a careful balance of several options. They show that imposing a tax on congestion externalities may need a reconfiguration of all taxes, and that a reduction of labor taxes is not necessarily the best option ${ }^{1}$.

This paper contributes to this line of research by analyzing the importance of revenue allocation when heterogeneous drivers use a congested network. We wonder whether taking into account differences across road users and redistribution objectives for transport policy can change the welfare effect implied by the recycling scheme.

Our approach is close to that of Parry and Bento (2001) but we add two dimensions to their model. First, instead of a choice between a congested road and uncongested public transit, we model two congested transport options.

\footnotetext{
${ }^{1}$ Proost and Van Regemorter (1995) apply this idea to a macro-economic disequilibrium framework.
} 
They can be both roads or one of them can be public transit. Allowing congestion on the untolled alternative is particularly interesting because it implies that the toll not only brings efficiency gains in the transport market but also efficiency losses in the form of increased congestion in the rest of the network (see e.g. Rouwendal and Verhoef, 2004). Second, Parry and Bento consider homogeneous consumers without paying attention to income distribution issues. However, we know that at the origin of labor taxes there is often the income distribution objective. With this in mind, we model laborforce heterogeneity in the form of differences in labor productivity between two types (low- and high-income) of workers. Differences in productivity imply differences in values of time. This in turn determines the sorting of commuters over the tolled and the untolled route (see e.g. Small and Yan, 2001; de Palma and Lindsey, 2004). Tolling the faster route will tend to attract the most productive commuters. Therefore, the tax can be imposed on high-income consumers and can be used either to redistribute resources to low-income consumers or to obtain additional efficiency gains by lowering labor taxes for all commuters.

Our analysis shows that the optimal toll differs from the Pigouvian tax. The toll can be lower or higher than the marginal external cost on the tolled road. The magnitude of the deviation depends on several aspects: the equity concerns, who uses the tolled road, who benefits from redistribution and how easily consumers switch to other alternatives. A numerical exercise provides two significant insights. First, when accounting for heterogeneity, tolling off those that are least able to pay for the toll can be welfare improving, on the condition that the revenue recycling scheme benefits them. Consequently, if income distribution concerns seek to favor the least productive workers, the policymaker would prefer to recycle toll revenues through poll transfers. Second, assumptions about the relationship between the tolling policy and congestion in the rest of the network determine the effects of the recycling scheme on labor supply. Neglecting congestion on alternative routes may result in an overestimation of benefits from the tolling policy.

This paper is organized as follows. In Section 2, we develop an analytical model and analyze the problem with homogeneous households. In Section 3 , we introduce heterogeneity in labor productivity and define four different equilibriums of road use. In Section 4, we analyze the social planner's problem and derive the optimal tolling rules for the different equilibriums and for two ways of recycling the toll revenues: poll transfers and labor tax 
cuts. In section 5 , we present a numerical illustration. In the last section we conclude.

\section{The household's problem: road choice}

We start with a simple model - in the spirit of Parry and Bento (2001) of a representative household whose utility function depends on aggregate consumption of market goods ( $X$, whose price is normalized to one), leisure time $\left(t_{L}\right)$, and the disutility of commuting ${ }^{2}(\Psi(\cdot))$. The household owns a car and uses it to commute to work by either one of the two parallel congested roads (routes $U$ and $T$ ) that connect residential areas to workplaces. Total number of worked days in a period $(D)$ is the sum of the number of days the household commutes by road $U$ and by road $T\left(D_{U}\right.$ and $\left.D_{T}\right)$.

$$
\mathcal{U}\left(X, t_{L}, D_{U}, D_{T}\right)=U\left(X, t_{L}\right)+\Psi\left(D_{U}, D_{T}\right)
$$

A congestion toll $(\tau)$ related to distance $(d)$ is applied on one of the two roads (route $T$ ), while the other (route $U$ ) remains untolled. Households choose which route to use to commute to work, $U$ or $T$. Thus, the budget constraint is:

$$
X+g d_{U} D_{U}+(g+\tau) d_{T} D_{T} \leq \varepsilon w\left(1-\tau_{w}\right)\left(D_{U}+D_{T}\right)+G
$$

The right-hand side of (2) corresponds to total household's income composed of work income and a head subsidy $(G)$. Work income in a period is the product of the daily net wage and the number of days worked in the period, where $\varepsilon$ is labor productivity per day, $w$ is the gross daily wage and $\tau_{w}$ is a tax levied on wage income. We assume that households are homogeneous in all respects except that they exhibit different exogenous levels of labor productivity. Thus, for the same level of labor supplied, high-productivity households get a higher income than low-productivity households.

The left-hand side of (2) corresponds to household expenditures on aggregate consumption and commuting. Each day of work requires a commuting round trip that involves time and monetary costs. When commuting by the

\footnotetext{
${ }^{2}$ The separability of the utility function implies that the amount of labor supplied is independent of the road choice.
} 
untolled road, only fuel costs are relevant ${ }^{3} \cdot g$ represents fuel price per kilometer, $g=c_{g}\left(1+\tau_{g}\right)$, where $c_{g}$ is the resource fuel cost (which takes into account vehicle fuel efficiency) and $\tau_{g}$ the fuel tax. Commuting by the tolled road implies paying for the fuel consumption plus the toll. However, this road allows faster trips, while the untolled road requires more time and higher fuel consumption due to a longer distance: $d_{U}=\beta d_{T}$ with $\beta>1$.

Households also face a time constraint:

$$
\bar{t}=D_{U}+D_{T}+t_{U} d_{U} D_{U}+t_{T} d_{T} D_{T}+t_{L}
$$

The household's time endowment during a period $(\bar{t})$ equates the sum of labor supplied, commuting time and leisure time. $t_{U}$ and $t_{T}$ are two different functions of time per unit of distance (e.g. the inverse of the speed -h/km). Households choose how many days to work in a period (hours of work per day are fixed $\left.^{4}\right)$, and how to commute to work. By choosing the optimal number of workdays $\left(D_{T}\right.$ and $\left.D_{U}\right)$ in a period, households indirectly set total income and total leisure time during the period.

The first-order conditions of maximizing utility (1) subject to (2) and (3) are (see Appendix B for detailed derivations):

$$
\begin{gathered}
\varepsilon w\left(1-\tau_{w}\right)-\frac{U_{t_{L}}}{U_{X}}=g d_{U}+t_{U} d_{U} \frac{U_{t_{L}}}{U_{X}}-\frac{\Psi_{D_{U}}}{U_{X}}, \\
\varepsilon w\left(1-\tau_{w}\right)-\frac{U_{t_{L}}}{U_{X}}=(g+\tau) d_{T}+t_{T} d_{T} \frac{U_{t_{L}}}{U_{X}}-\frac{\Psi_{D_{T}}}{U_{X}} .
\end{gathered}
$$

These expressions equate the private benefit from an extra day of work (daily net wage minus the value of daily leisure time foregone by working) with the generalized private cost of commuting (monetary and time costs). The monetary cost of transport consists of the fuel consumption charge in

\footnotetext{
${ }^{3}$ We consider that costs such as maintenance, insurance, vehicle ownership taxes, etc., are constant, since they do not vary with the level of congestion.

${ }^{4}$ This is a typical assumption in the related literature (see e.g. Parry and Bento, 2001; Van Dender, 2003). However, it can be argued that hours per day can also be chosen. By using a labor supply model that allows for optimal choice of both daily work hours and number of workdays, Gutierrez-i Puigarnau and van Ommeren (2009) show that commuting costs can increase daily hours worked. However, they find that the effect on total labor supply is ambiguous
} 
the case of commuting by the untolled road (4), whereas it consists of the fuel consumption plus the toll when commuting by the tolled road (5).

As a result of considering time as a resource, we get the monetary value of time for each household $\left(U_{t_{L}} / U_{X}\right)$. This is the ratio between the Lagrange multiplier of the time constraint and the Lagrange multiplier of the income constraint (see Appendix B). The value of spending time in transport ${ }^{5}$ (Value of Transport Time, VTT) is represented in (4) and (5) by the value of time foregone by commuting plus the marginal disutility of commuting (VTT = $t_{R} d_{R}\left(U_{t_{L}} / U_{X}\right)-\left(\Psi_{D_{R}} / U_{X}\right)$, where $\left.R=U, T\right)$.

Equating (4) and (5) yields the Wardrop equilibrium condition ${ }^{6}$ in which the two roads have equal generalized prices ${ }^{7}$ :

$$
\tau=g(\beta-1)+\left(\beta t_{U}-t_{T}\right) \frac{U_{t_{L}}}{U_{X}}+\frac{1}{d_{T}}\left(\frac{\Psi_{D_{T}}}{U_{X}}-\frac{\Psi_{D_{U}}}{U_{X}}\right) .
$$

This expression indicates that households are indifferent to taking either of the two roads when the toll imposed on road $T$ equals the extra-cost of commuting by road $U$. That is, the extra-gasoline and the extra travel time costs plus the difference between the marginal disutility of commuting by each $\operatorname{road}^{8}$.

A household's individual decision depends on its own value of time $\left(U_{t_{L}} /\right.$ $U_{X}$ ), which also determines its willingness to pay for a trip. The opportunity cost of time indirectly depends on labor productivity. As high-productivity households normally get higher wages, they should exhibit higher values of leisure time, whereas low-productivity households exhibit lower values, i.e. $U_{t_{L}}^{h} / U_{X}^{h}>U_{t_{L}}^{\ell} / U_{X}^{\ell}$ where $h$ and $\ell$ indicate highly- and less-productive households, respectively. Thus, a sufficiently high toll should make highproductivity households stay on the tolled road and therefore save highvalued time. In contrast, as low-productivity households have lower budgets,

\footnotetext{
${ }^{5}$ For a detailed explanation of travel time valuation, see Small and Verhoef (2007) and Jara-Diaz (2000).

${ }^{6}$ Wardrop principle: "For a given origin-destination pair of substitute roads, all used routes should have equal average cost and there should be no unused routes with lower costs" (Small and Verhoef, 2007).

${ }^{7} \mathrm{We}$ assume we can exclude corner solutions where only one of the two roads is used.

${ }^{8}$ If the marginal disutility of commuting is the same by the two roads $\Psi_{D_{T}} / U_{X}=$ $\Psi_{D_{U}} / U_{X}$, the right hand side of condition (6) is reduced to the extra-gasoline and extratime costs: $\tau=g(\beta-1)+\left(\beta t_{U}-t_{T}\right) U_{t_{L}} / U_{X}$.
} 
they should be more sensitive to monetary cost and should prefer taking the untolled road in order to save money.

We finally define the differentiable demand functions for each road $D_{U}^{*}=$ $D_{U}\left(\tau_{g}, \tau_{w}, \tau, t_{U}, w, \varepsilon\right), D_{T}^{*}=D_{T}\left(\tau_{g}, \tau_{w}, \tau, t_{T}, w, \varepsilon\right)$. Assuming that they exist allows us to get the household's indirect utility function $v\left(\tau_{g}, \tau_{w}, \tau, t_{T}, t_{U}, w, \varepsilon\right.$, $G$ ) as a function of exogenous parameters (see Appendix B).

\section{Use of the congested roads by heterogeneous households}

In the presence of congestion, households take into account their own travel cost but not the external cost imposed on other users $\left(\partial t_{T} / \partial D_{T}>0\right.$, and $\left.\partial t_{U} / \partial D_{U}>0\right)$. First-best pricing calls for tolling both roads at their marginal external costs. However, we are interested in analyzing the secondbest configuration where only one of the two roads can be tolled. In this section we study the user equilibrium. The properties of the user equilibrium will be instrumental in the derivation of the optimal taxes in the next section.

We assume that the economy is populated by $n^{h}$ highly productive and $n^{\ell}$ less productive households ( $\operatorname{such}$ that $n^{h}+n^{\ell}=N$ ). Both kinds of households independently choose the number of trips they make in a period $D_{R}^{i}(i=$ $\ell, h$ and $R=U, T)$. As households differ in their willingness to pay for commuting, differentiating them according to the road used may be useful. As a start, we assume consumers with higher values of time to take road $T$ and consumers with lower values of time to take road $U^{9}$.

Let us assume for a moment that there is no specific preference for a road. That is, $\Psi_{D_{T}^{\ell}} / U_{X}^{\ell}=\Psi_{D_{U}^{\ell}} / U_{X}^{\ell}$ and $\Psi_{D_{T}^{h}} / U_{X}^{h}=\Psi_{D_{U}^{h}} / U_{X}^{h}$. From the right-hand side of equations (4) and (5) we can compare the generalized cost (per unit of distance) of commuting for each road per type of household:

$$
\begin{gathered}
\underbrace{\tau+g+t_{T}\left(\sum n^{i} D_{T}^{i}\right) \frac{U_{t_{L}}^{h}}{U_{X}}}_{c_{T}^{h}} \leq \underbrace{\beta\left(g+t_{U}\left(\sum n^{i} D_{U}^{i}\right) \frac{U_{t_{L}}^{h}}{U_{X}}\right)}_{c_{U}^{h}}, \\
\underbrace{\tau+g+t_{T}\left(\sum n^{i} D_{T}^{i}\right) \frac{U_{t_{L}}^{\ell}}{U_{X}}}_{c_{T}^{\ell}} \geq \underbrace{\beta\left(g+t_{U}\left(\sum n^{i} D_{U}^{i}\right) \frac{U_{t_{L}}^{\ell}}{U_{X}}\right)}_{c_{U}^{\ell}} .
\end{gathered}
$$

\footnotetext{
${ }^{9}$ As road $T$ attracts those consumers willing to pay more for faster commuting.
} 
These conditions compare the total generalized cost of commuting by $T$ (left hand-side) with the cost of commuting by $U$ (right hand-side) for a highproductivity household (7) and for a low-productivity household (8). When a household takes the decision to commute by one of the roads, it already knows the cost of time it will face: total time required multiplied by its own value of time ${ }^{10}$. Time required (per unit of distance) by each road is an increasing function ${ }^{11}$ of total traffic volume. $U_{t_{L}}^{h} / U_{X}^{h}$ and $U_{t_{L}}^{\ell} / U_{X}^{\ell}$ represent the value of time for high- and low-productivity households, respectively.

From (7) and (8) we establish four different equilibriums of use of the roads by the households ${ }^{12}$, similar to those established in Small and Yan (2001). Equations (7) and (8) are developed for each equilibrium in Appendix C .

\subsection{Separating equilibrium}

This is the case where high-income households commute only by $T\left(D_{U}^{h}=\right.$ 0 ) and low-income households only by $U\left(D_{T}^{\ell}=0\right)$. This requires equations (7) and (8) to hold both with inequality (i.e. $c_{T}^{h}<c_{U}^{h}$ and $c_{T}^{\ell}>c_{U}^{\ell}$ ).

\subsection{Partially separating equilibrium with the low-income group separated}

In this case high-income households commute by $T$ and $U$, and lowincome households commute only by $U\left(D_{T}^{\ell}=0\right)$. This requires equation (7) to hold with equality and (8) with inequality (i.e. $c_{T}^{h}=c_{U}^{h}$ and $c_{T}^{\ell}>c_{U}^{\ell}$ ).

\subsection{Partially separating equilibrium with the high-income group separated}

In this case high-income households commute by $T\left(D_{U}^{h}=0\right)$, and lowincome households commute by $T$ and $U$. This requires equation (7) to hold with inequality and (8) with equality (i.e. $c_{T}^{h}<c_{U}^{h}$ and $c_{T}^{\ell}=c_{U}^{\ell}$ ).

\footnotetext{
${ }^{10}$ It implicitly assumes consumers are informed about current traffic congestion conditions on both roads, by for example, electronic bulletin boards or services such as traffic forecast, and of course, by their own experience.

${ }^{11} t_{R}\left(\sum n^{i} D_{R}^{i}\right)$ in (7) and (8) denotes the time function for each one of the roads.

${ }^{12}$ If we had used a continuum of household types, as in Verhoef and Small (2004), every type of household would probably have used only one route.
} 


\subsection{Pooling equilibrium}

In this case both kinds of households commute by $T$ and $U$. If both equations hold with equality, both types of households will be indifferent towards taking either of the two roads. This can occur at the no-toll equilibrium ${ }^{13}$ $(\tau=0)$ and for low toll values. This depends on how large the parameter $\beta$ is (the larger $\beta$ the more difficult it is to obtain a pooling equilibrium) and on the value of time of low-income commuters (the lower value of time of the low-income group the more difficult it is to obtain a pooling equilibrium).

\section{The social planner's problem: the optimal toll}

The government raises revenues to finance public goods $F$ and a head subsidy $G$, using three tax instruments: fuel taxes $\left(\tau_{g}\right)$, tolls $(\tau)$ and labor taxes $\left(\tau_{w}\right)$. We assume equal labor tax rates for both types of households ${ }^{14}$. The government maximizes social welfare ${ }^{15} \mathbb{W}=\sum_{i} n^{i} \theta^{i} v^{i}\left(\tau_{g}, \tau_{w}, \tau, t_{U}, t_{T}, w\right.$, $\left.\varepsilon^{i}, G\right)$, subject to the following budget constraint:

$$
w \tau_{w} \sum_{i} \sum_{R} n^{i} \varepsilon^{i} D_{R}^{i}+\tau_{g} c_{g} \sum_{i} \sum_{R} n^{i} d_{R} D_{R}^{i}+\tau \sum_{i} n^{i} d_{T} D_{T}^{i}=F+N G .
$$

Each household chooses the optimal number of commuting trips $\left(D_{R}^{i}\right)$ that maximizes its individual utility. The budget constraint (9) varies as a function of the use of the roads by the households. Thus, each equilibrium implies a different budget constraint. In what follows, we analyze the optimal toll level for the four possible equilibriums studied in the previous section. For each case, toll revenues are returned to the individuals either through poll transfers or through labor-tax cuts.

\footnotetext{
${ }^{13}$ As Small and Yan (2001) and de Palma and Lindsey (2004) show, this is a typical result of no-toll equilibrium

${ }^{14}$ This assumption is relaxed in the numerical illustration.

${ }^{15}$ This is a purely utilitarian social welfare function where increases or decreases in individual utilities translate into identical changes in social utility. Assumptions on the concavity of the utility function allow for the differentiation of the social marginal value of one unit of income over individuals. Aversion to income inequality is introduced via $\theta$, the social weight given by the government to each kind of household (with $\sum_{i} \theta^{i}=1$ ).
} 


\subsection{Separating equilibrium}

In this equilibrium high-income households take only road $T$ and lowincome households take only road $U$. Although this case might not seem realistic, it is useful as a benchmark that allows comparison with the more complex cases. The government's budget constraint (9) becomes:

$$
w \tau_{w}\left(n^{h} \varepsilon^{h} D_{T}^{h}+n^{\ell} \varepsilon^{\ell} D_{U}^{\ell}\right)+\tau_{g} c_{g} d_{T}\left(n^{h} D_{T}^{h}+\beta n^{\ell} D_{U}^{\ell}\right)+\tau d_{T} n^{h} D_{T}^{h}=F+N G .
$$

By assumption in the separating equilibrium, the $h$-group continues to use only the tolled road but reduces the number of trips made on this road as the toll increases. On the other hand, the $\ell$-group keeps the number of trips on $U$ fixed.

\subsubsection{Toll revenues used to finance head transfers}

We derive the optimal congestion tax $\left(\tau_{p t}\right.$, where $p t$ stands for poll transfers) that maximizes social welfare when revenues are returned to households as poll transfers.

$$
\tau_{p t}=\frac{1}{1-\phi_{p t} \vartheta \xi} \underbrace{\frac{\partial t_{T}}{\partial D_{T}^{h}} \frac{U_{t_{L}}^{h}}{U_{X}^{h}} D_{T}^{h}}_{\text {mecc }}-\frac{1-\phi_{p t} \vartheta}{1-\phi_{p t} \vartheta \xi}(\underbrace{\tau_{g} c_{g}+\tau_{w} \frac{w \varepsilon^{h}}{d_{T}}}_{\text {other taxes per trip }})
$$

where $\phi_{p t}=\frac{n^{\ell}}{N}, \vartheta=\left(1-\frac{U_{X}^{\ell}}{U_{X}^{h}} \frac{\theta^{\ell}}{\theta^{h}}\right)$ and $\xi=1+\frac{1}{\epsilon_{D_{T}^{h}}^{\tau}}$, with $\epsilon_{D_{T}^{h}}^{\tau}$ the elasticity of demand of high-income households for the tolled road (see Appendix D.1.1).

The optimal congestion toll has two main components, the marginal external congestion cost (mecc) and a correction for the other taxes levied per trip $^{16}$. The mecc measures the increase in time cost to all road users caused by an extra trip per period. In equation (11), it is represented by the product of: the increase in commute time from an additional trip $\left(\partial t_{T} / \partial D_{T}^{h}\right)$, the value of time of the commuter $\left(U_{t_{L}}^{h} / U_{X}^{h}\right)$, and the number of trips made per period $D_{T}^{h}$. Other taxes per trip appear in (11) as the complementary relationship between work-related trips and the labor market ensures that all

\footnotetext{
${ }^{16}$ Given the fully separating assumption, this optimal toll does not incorporate the typical second-best term that corrects for the distortion of leaving one of the roads untolled. This will however appear in the partially separating equilibriums.
} 
taxes (per kilometer) levied per day of work serve to tackle the externality caused by each day of work, namely congestion. Thus, for example, if the sum of the fuel and the labor tax exceeds the mecc, rather than taxing road $T$ commuters, the government should subsidize them. Equation (11) therefore suggests an optimal combination of the toll, the fuel tax and the labor tax, rather than a unique optimal toll level.

Each term in (11) is multiplied by a factor that depends on the government distribution concerns $(\vartheta)$. The governmental distribution concerns depend on the ratio of the marginal utility of income of both types of consumers $\left(U_{X}^{\ell} / U_{X}^{h}\right)$, and the relative social weight given to a unit of utility of a poor individual with respect to a rich individual $\left(\theta^{\ell} / \theta^{h}\right)$. Normally, $U_{X}^{\ell} / U_{X}^{h}>1$ as the marginal utility of income declines with the level of income. Similarly, $\theta^{\ell} / \theta^{h}>1$ when the decision maker attaches a higher weight to less-productive consumers.

If there was no difference between the groups $\left(U_{X}^{\ell}=U_{X}^{h}\right)$ and the government attached the same weight to both of them $\left(\theta^{\ell}=\theta^{h}\right)$, the toll should equal the difference between the mecc and the sum of the other taxes ${ }^{17}$. When this is not the case, however, the revenue raising effect implied by the price elasticity of the tolled road $\left(\epsilon_{D_{T}^{h}}^{\tau}\right)$ plays an important role. If the weight attached by the government to the poor is higher and the demand for the tolled road is inelastic (elastic), the toll should be higher (lower) than the difference between the mecc and the sum of the other taxes.

This suggests that a greater concern for the welfare of the poor leads to the use of the toll as an instrument to redistribute income when the demand for the tolled road is inelastic (in this equilibrium road $T$ is used only by the rich). However, when demand is elastic the use of the toll as an instrument to redistribute income is limited, as every euro of additional toll revenues then has a high efficiency cost.

\subsubsection{Toll revenues used to cut labor taxes}

Following the same procedure, we obtain the optimal toll $\left(\tau_{l t}\right.$, where $l t$ stands for labor tax cuts) when the incremental toll revenues are used to cut

\footnotetext{
${ }^{17}$ Therefore (11) contains Parry and Bento's (2001) result $(\tau=m e c c)$ as a special case: homogeneous consumers, no redistribution concerns and no other taxes levied per trip.
} 
labor tax rates:

$$
\tau_{l t}=\frac{1}{1-\phi_{l t} \vartheta \xi} \frac{\partial t_{T}}{\partial D_{T}^{h}} \frac{U_{t_{L}}^{h}}{U_{X}^{h}} D_{T}^{h}-\frac{1-\phi_{l t} \vartheta}{1-\phi_{l t} \vartheta \xi}\left(\tau_{g} c_{g}+\tau_{w} \frac{w \varepsilon^{h}}{d_{T}}\right),
$$

where $\phi_{l t}=\frac{n^{\ell} \varepsilon^{\ell} D_{U}^{\ell}}{n^{h} \varepsilon^{h} D_{T}^{h}+n^{\ell} \varepsilon^{\ell} D_{U}^{\ell}}$ (see Appendix D.1.2). This expression differs from (11) in that $\phi_{l t}$ takes into account the proportion of labor supplied by low-productivity households. Redistributing income through the labor tax implies that what drives equity aspects of the toll level is the proportion of labor supplied by low-productivity consumers $\left(\phi_{l t}\right)$ rather than their proportion in the economy $\left(\phi_{p t}\right)$. It is the proportion $\phi_{l t}$ that will determine the extent to which the poor will benefit from a labor tax cut.

\subsection{Partially separating equilibrium with the low-income group separated}

In this equilibrium high-income households take $\operatorname{road} T$ and $\operatorname{road} U$, and low-income households take only road $U$. As the roads are substitutes, we assume that if the toll increases, high-income consumers reduce the number of trips they make by road $T$ and increase the number of trips they make by road $U$. To keep things simple we assume that low-income users do not change their number of trips by road $U$ as the toll increases ${ }^{18}$. Thus, the government's budget constraint becomes:

$$
\begin{aligned}
w \tau_{w}\left(n^{h} \varepsilon^{h}\left(D_{T}^{h}+D_{U}^{h}\right)+n^{\ell} \varepsilon^{\ell} D_{U}^{\ell}\right) & +\tau_{g} c_{g} d_{T}\left(n^{h}\left(D_{T}^{h}+\beta D_{U}^{h}\right)+\beta n^{\ell} D_{U}^{\ell}\right) \\
& +\tau d_{T} n^{h} D_{T}^{h}=F+N G
\end{aligned}
$$

\subsubsection{Toll revenues used to finance head transfers}

When the incremental toll revenues are used to finance lump-sum transfers we get (see Appendix D.2.1):

$$
\begin{aligned}
\tau_{p t} & =\frac{1}{1-\phi_{p t} \vartheta \xi} \frac{U_{t_{L}}^{h}}{U_{X}^{h}}\left(\frac{\partial t_{T}}{\partial D_{T}^{h}} D_{T}^{h}+\frac{\partial t_{U}}{\partial D_{U}^{h}} D_{U}^{h} \beta D_{T U}^{h}\right) \\
& -\frac{1-\phi_{p t} \vartheta}{1-\phi_{p t} \vartheta \xi}\left(\tau_{g} c_{g}\left(1+\beta D_{T U}^{h}\right)+\tau_{w} \frac{w \varepsilon^{h}}{d_{T}}\left(1+D_{T U}^{h}\right)\right) .
\end{aligned}
$$

Because in this case high-income commuters have the possibility to exchange trips on road $T$ for trips on road $U$ as the toll increases, we get the

\footnotetext{
${ }^{18}$ This assumption is relaxed in the numerical illustration.
} 
term $D_{T U}^{h}=\partial D_{U}^{h} / \partial D_{T}^{h}<0$, which gives the number of trips added to $U$ per trip removed from $T^{19}$. Although equation (14) has the same structure as (11), it incorporates the marginal external congestion cost caused on road $U$ by the fraction of trips moved from $T$ to $U$. This is a typical second best result: mitigate the distortion on one market only to the extent that it does not aggravate the distortion on the other market (Small and Verhoef, 2007, p. 140). As before, (14) implies that the optimal toll should be set as a fraction of the difference between the mecc and other taxes per trip.

\subsubsection{Toll revenues used to cut labor taxes}

The optimal toll when the incremental toll revenues are used to cut labor taxes is given by (see Appendix D.2.2):

$$
\begin{aligned}
\tau_{l t} & =\frac{1}{1-\phi_{l t} \vartheta \xi} \frac{U_{t_{L}}^{h}}{U_{X}^{h}}\left(\frac{\partial t_{T}}{\partial D_{T}^{h}} D_{T}^{h}+\frac{\partial t_{U}}{\partial D_{U}^{h}} D_{U}^{h} \beta D_{T U}^{h}\right) \\
& -\frac{1-\phi_{l t} \vartheta}{1-\phi_{l t} \vartheta \xi}\left(\tau_{g} c_{g}\left(1+\beta D_{T U}^{h}\right)+\tau_{w} \frac{w \varepsilon^{h}}{d_{T}}\left(1+D_{T U}^{h}\right)\right),
\end{aligned}
$$

with $\phi_{l t}=\frac{n^{\ell} \varepsilon^{\ell} D_{U}^{\ell}}{n^{h} \varepsilon^{h}\left(D_{T}^{h}+D_{U}^{h}\right)+n^{\ell} \varepsilon^{\ell} D_{U}^{\ell}}$. This equation has the same structure as (14) and contains the externality-correction term. Again, the only difference between (14) and (15) is $\phi_{l t}$, which takes into account the proportion of labor supplied by low-productivity households as in (12).

Equations (14) and (15) imply therefore a toll level lower than that implied by (11) and (12), respectively, as the former includes a mecc reduced by the effect of traffic diversion.

\subsection{Partially separating equilibrium with the high-income group separated}

In this equilibrium high-income households take $\operatorname{road} T$, and low-income households take both roads. As before, we assume that if the toll increases, low-productivity consumers reduce the number of trips they make by road $T$ and increase the number of trips they make by road $U$. In addition, we assume that high-productivity consumers reduce their number of trips by

\footnotetext{
${ }^{19}$ This trade-off between roads $\left(\partial D_{U}^{h} / \partial D_{T}^{h}\right)$ affects the mecc and the second part of (14) since revenues collected from other taxes also depend on the road used.
} 
road $T$ only as a result of the toll increase. However, they do not move to road $U^{20}$. The government's budget constraint becomes:

$$
\begin{aligned}
w \tau_{w}\left(n^{h} \varepsilon^{h} D_{T}^{h}+n^{\ell} \varepsilon^{\ell}\left(D_{T}^{\ell}+D_{U}^{\ell}\right)\right) & +\tau_{g} c_{g} d_{T}\left(n^{h} D_{T}^{h}+n^{\ell}\left(D_{T}^{\ell}+\beta D_{U}^{\ell}\right)\right) \\
& +\tau d_{T}\left(n^{h} D_{T}^{h}+n^{\ell} D_{T}^{\ell}\right)=F+N G .
\end{aligned}
$$

The optimal toll, if revenues are used to make poll transfers, is as follows:

$$
\begin{aligned}
\tau_{p t}=\frac{1}{1-\phi_{p t} \vartheta-\zeta}[ & E_{D_{T}^{h}}^{\tau} \frac{U_{t_{L}}^{h}}{U_{X}^{h}} \frac{\partial t_{T}}{\partial D_{T}^{h}} D_{T}^{h} \\
& \left.+\frac{\theta^{\ell}}{\theta^{h}} E_{D_{T}^{\ell}}^{\tau} \frac{U_{t_{L}}^{\ell}}{U_{X}^{h}}\left(\frac{\partial t_{T}}{\partial D_{T}^{\ell}} D_{T}^{\ell}+\frac{\partial t_{U}}{\partial D_{U}^{\ell}} D_{U}^{\ell} \beta D_{T U}^{\ell}\right)\right] \\
-\frac{1-\phi_{p t} \vartheta}{1-\phi_{p t} \vartheta-\zeta}[ & \tau_{g} c_{g}\left(E_{D_{T}^{h}}^{\tau}+E_{D_{T}^{\ell}}^{\tau}\left(1+\beta D_{T U}^{\ell}\right)\right) \\
& \left.+\tau_{w} \frac{w}{d_{T}}\left(E_{D_{T}^{h}}^{\tau} \varepsilon^{h}+E_{D_{T}^{\ell}}^{\tau} \varepsilon^{\ell}\left(1+D_{T U}^{\ell}\right)\right)\right],
\end{aligned}
$$

where $\zeta=\frac{\sum_{i} n^{i} D_{T}^{i}+\vartheta \ell D_{T}^{\ell}}{\sum_{i} n^{i} D_{T}^{i} \epsilon_{D_{T}^{i}}^{\tau}}$ and $E_{D_{T}^{i}}^{\tau}=\frac{n^{i} D_{T}^{i} \epsilon_{D_{T}^{i}}^{\tau}}{\sum_{i} n^{i} D_{T}^{i} \epsilon_{D_{T}^{\tau}}^{\tau}}$ (see Appendix D.3).

Although (17) is more complex than previous equations, we can identify the same structure. The optimal toll should be set as a fraction of the difference between the externality-correction term and the level of other taxes per trip. The externality-correction term here consists of three terms: the mecc imposed on road $T$ by both kinds of households and the mecc imposed on road $U$ by low-income households.

In this case, the value of time and price elasticity of demand of both types of consumers appears in the equation as they both take the tolled road. Each term in this expression is weighted by a factor $\left(E_{D_{T}^{i}}^{\tau}\right)$ that depends on the price elasticity of each type of household, as the response of consumers to toll increases depends on their price elasticity. As indicated by Small and Verhoef (2007, p. 145), when tolls cannot be differentiated among user groups, the second-best toll depends on a weighted average (by the price sensitivity of demand) of the marginal external costs for the different groups.

We limit this section to the case of poll-transfer recycling as labor-tax recycling does not add additional insights compared to the previous section.

\footnotetext{
${ }^{20}$ This assumption is relaxed in the numerical illustration.
} 


\subsection{Pooling equilibrium}

We mention this case for the sake of completeness, yet it is highly unlikely that this will be a welfare maximizing equilibrium given that a pooling equilibrium exists for zero or small tolls only. It is developed in Appendix D.4.

\subsection{The optimal tolling rule: summary}

When only one road can be tolled we know this allows for efficiency gains as high-value-of-time commuters prefer the tolled road. When a separating equilibrium exists, toll revenues can be used to reduce existing labor taxes (maximizing efficiency gains) or to decrease poll taxes (maximizing equity effects). Equity concerns can push the toll above the marginal external congestion cost as this allows to redistribute more revenues to the poor part of the population. When there is only a partial separating equilibrium the rule becomes more complex as one now also has to pay attention to the diversion of drivers to the non-tolled congested route. This calls for lower tolls and limits the redistribution potential of the toll.

\section{Numerical illustration}

This section presents the results of a numerical simulation ${ }^{21}$ of a road network such as described in Section 2. Although this exercise is merely for illustrative purposes, we calibrate the model with French data in order to be coherent and give a realistic flavor to the illustration. Data for the labor and transport markets are taken from the National Institute of Statistics and Economics Studies -INSEE (Fesseau et al. (2009) and Baccani et al. (2007), respectively). Sections 5.1 and 5.2 present the parameter values used to calibrate the model and the simulation results for the base case. Next, Sections 5.3 and 5.4 examine the effect of changes in some key parameters.

\subsection{Calibration}

We choose an urban area of 500.000 inhabitants ${ }^{22}$ where the average distance of a daily (round) commuting trip is $50 \mathrm{Km}$. The slope of the congestion function is such that the free-flow speed $(60 \mathrm{Km} / \mathrm{h})$ is reduced to one-third

\footnotetext{
${ }^{21}$ The algorithm was written in GAMS.

${ }^{22}$ With a labor force participation of $70 \%$ and an unemployment rate of $15 \%$.
} 
in peak hours (this implies a highly congested commuting traffic). Travel time increases linearly with traffic volume. Both roads exhibit the same congestion functions, but the secondary network (i.e. the untolled road) is 1.5 times longer than the tolled road.

We define a household's utility function ${ }^{23}$ separable in two terms, the utility of consumption/leisure and the disutility of traveling:

$$
\mathcal{U}\left(X, t_{L}, D_{U}, D_{T}\right)=\left(\alpha_{X} X^{\frac{\sigma-1}{\sigma}}+\left(1-\alpha_{X}\right) t_{L}^{\frac{\sigma-1}{\sigma}}\right)^{\frac{\sigma}{\sigma-1}}+\alpha_{C}\left(D_{U}+D_{T}\right) .
$$

We choose $\sigma=1.52$ to be consistent with values of consumption/leisure elasticity of the related literature ${ }^{24} . \alpha_{X}$ is chosen to imply (on average) around 200 days of work per year. We set $\alpha_{C}=-1$ and give no particular weight to any of the roads, so that the marginal disutility of traveling for any of the routes is the same ${ }^{25}$.

There are two groups of workers that differ only in their labor productivity. The labor productivity of high-productivity households is around four times that of low-productivity households ${ }^{26}$. There is a higher proportion of low-productivity workers in the economy (65\%). We assume wage tax rates of $22 \%$ and $30 \%$ for low- and high-productive households ${ }^{27}$, respectively, and 8 hours of work per day. The gasoline tax is $235 \%$ of producer prices (E.C., 2009 , p. 11) and the vehicle fuel efficiency is 10 litres per $100 \mathrm{Km}^{28}$.

The constraints of this maximization problem are those described in (2) and (3). Thus, each household chooses, with perfect knowledge of the travel conditions on the network $\left(t_{R}\left(\sum n^{i} D_{R}^{i}\right)\right)$, the route and the number of com-

\footnotetext{
${ }^{23}$ Similar functions are used in Parry and Bento (2001) and Van Dender (2003).

${ }^{24}$ See Parry and Bento (2001) p.658 for a discussion of empirical evidence of this parameter.

${ }^{25}$ This implies that the roads are perfect substitutes from the consumer perspective. This reflects the consumer taste and has no relation with the characteristics of the roads.

${ }^{26}$ According to Fesseau et al. (2009) the best-off households have five times as much disposable income as the most modest. However this is considering total disposable income, without distinguishing between the source of income. When excluding returns on financial investments and property income, so that labor income is better accounted for, the difference in productivity decreases.

${ }^{27}$ This corresponds to the average rate of social contributions in Fesseau et al. (2009).

${ }^{28}$ This might seem high compared to current European standards of fuel efficiency, but we deal with congested urban traffic.
} 
muting trips. When a toll is imposed, toll extra-revenues are recycled in one of two ways: poll transfers and labor tax reductions.

\subsection{Base-case results}

We first concentrate on changes in the transport market. When there is no toll (the no-toll equilibrium-NTE), $69 \%$ of total traffic is concentrated on road $T$. This makes $T$ highly congested. The average speed of a trip on this road is around $20 \mathrm{Km} / \mathrm{h}$, whereas on $U$ it is $31 \mathrm{Km} / \mathrm{h}$. Figure 1 depicts the number of trips that the representative household of each type makes in a period, as a function of the toll $(€ / \mathrm{V}-\mathrm{Km})$, in the case of labor-tax $\operatorname{cuts}^{29}$.
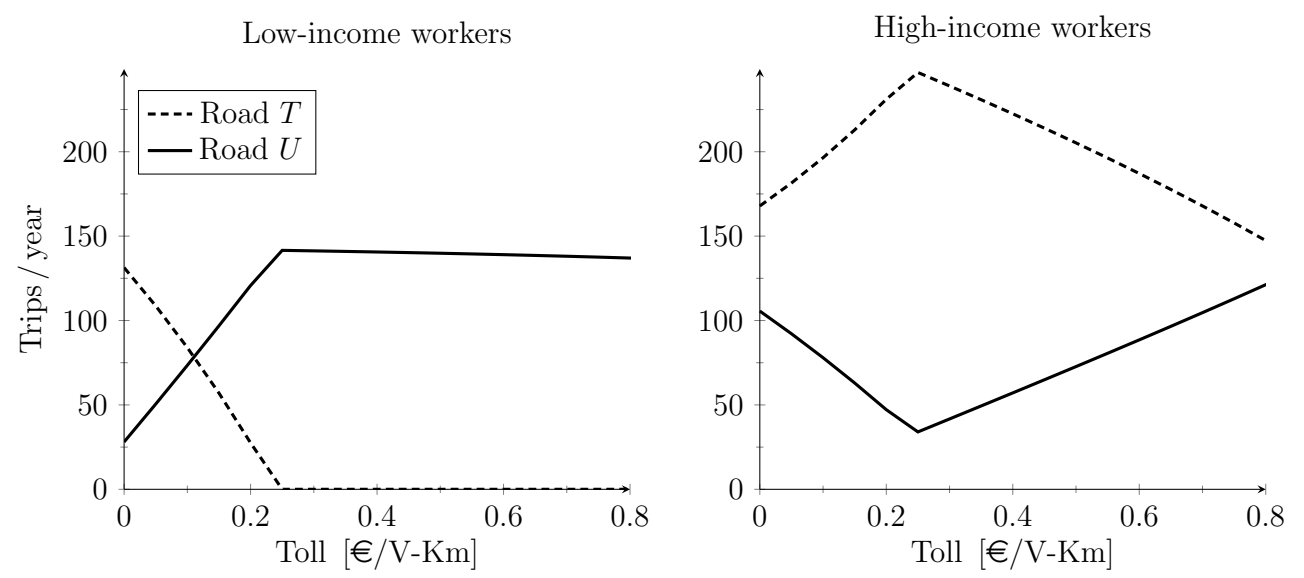

Figure 1: Trips per household in the base case (labor-tax recycling)

The two types of workers react differently to the toll. At the NTE lowand high-income consumers commute mainly by road $T$. Although this road is highly congested, it is shorter and allows less fuel-consuming trips. When the toll is imposed, low-income consumers reduce the number of trips on $T$ and go to $U$. But high-income consumers react differently: they exchange trips on $U$ by trips on $T$. As they can pay for the toll, they can take advantage of the reduction of congestion on $T$ resulting from low-income commuters leaving this road ${ }^{30}$. This is true until the point where the toll approaches $0.25 € / \mathrm{V}-\mathrm{Km}$.

\footnotetext{
${ }^{29}$ Results from poll transfers are very similar in terms of road use.

${ }^{30}$ The VOT for low- and high-income consumers are 3.89 and $18.43 € / \mathrm{h}$, respectively.
} 
For low toll values $(0 \leq \tau<0.25)$ we are in the Pooling Equilibrium where both kinds of workers commute by both roads. For higher toll values $(\tau \geq 0.25)$ we are in the Partially Separating Equilibrium with the low-income group separated. In this case, low-income consumers are priced off road $T^{31}$, given that the cost of commuting by $T$ exceeds the cost of commuting by $U$. High-income consumers, on the other hand, start switching to road $U$ since paying a higher toll level no longer compensates the gain in time.

Given that road $T$ allows faster and less fuel-consuming trips than the alternative, imposing a toll helps to reduce congestion on this road. At $\tau=0.25$ (the level that allows the separating regime under labor-tax cuts), for instance, the reduction of traffic on $T$ compared with traffic at the NTE is around $15 \%$ (the average speed rises from 20 to $26 \mathrm{Km} / \mathrm{h}$ ). But this reduction comes at the expense of an increase of traffic on $U$ of $35 \%$ compared with the NTE (the average speed falls from 31 to $24 \mathrm{Km} / \mathrm{h}$ ). As a consequence, the reduction of congestion does not benefit all commuters in the same way. Given that low-productive workers use only $\operatorname{road} U$ at $\tau=0.25$, their commuting time (per commuter) at this point increases by $12 \%$ whereas the commuting time for highly-productive workers falls by $14 \%$ (compared with the NTE).

Now we turn to the effects on the labor market. Reduced congestion induces a positive feedback effect, that mitigates the negative impact of the toll, but this holds only for highly productive workers (left panel Figure 2). The impact of the toll on the less productive workers is negative. Given the large losses on the less productive labor market, the impact on aggregate labor supply (in days, not in product) ends up negative (right panel Figure 2).

This differs from Parry and Bento (2001). Our results suggest that, when labor-force heterogeneity and congestion on the untolled alternative are accounted for, using toll revenues to reduce distortionary labor taxes does encourage labor force participation but only among the most productive workers (those able to pay for the toll). Similar results are found for poll transfers. This means that, both types of revenue allocation can discourage labor force participation at the margin. Our results still show, however, that labor sup-

\footnotetext{
${ }^{31}$ Specifically, low-income consumers are tolled off road $T$ at $\tau=0.23$ for poll transfers and $\tau=0.25$ for labor-tax cuts.
} 


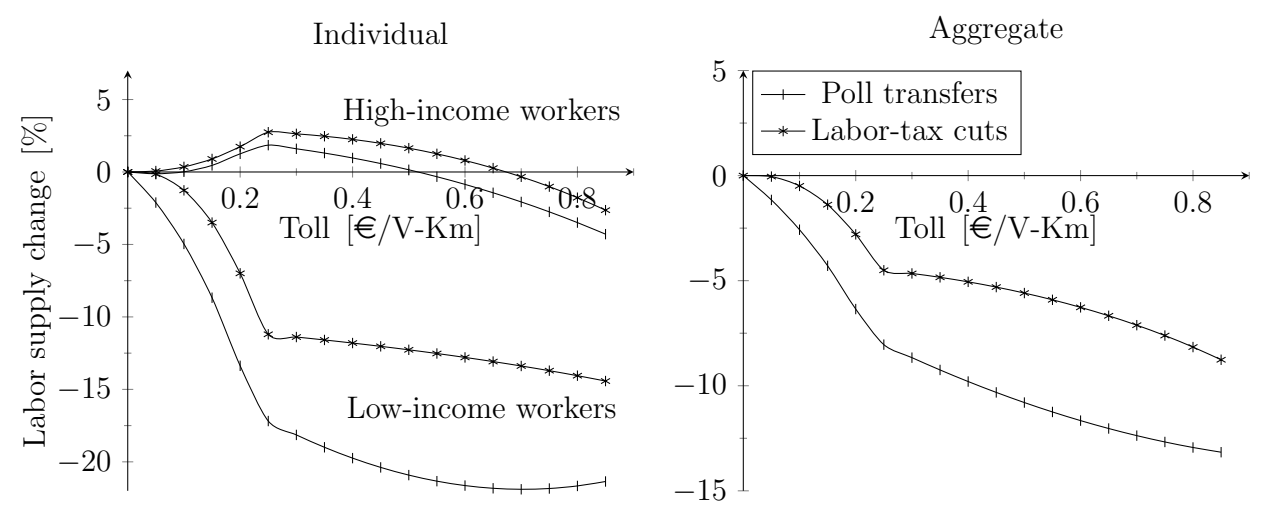

Figure 2: Labor supply in the base case: per type of household (left) and aggregate (right)

ply would decline more when toll revenues are used to make poll transfers instead of labor tax cuts.

Welfare effects of both policies are depicted in Figure 3 (the vertical axis shows the change in individual welfare, in monetary terms, compared with welfare at the $N T E$ ). There is a clear difference between the two scenarios of revenue use across the income groups. Low-income consumers benefit in the case of head transfers. Recycling via labor-tax cuts is welfare reducing for them. On the other hand, high-income consumers benefit from both measures but the welfare gains are (slightly) higher when revenues are redistributed through labor-tax cuts. This is because, given the same percentage-point reduction of the labor tax for both groups, the resulting head subsidy is lower (higher) than the tax rebate that a high-income (low-income) household gets. Labor-tax cuts benefit the h-households given that, besides the gains from reduced congestion, they receive the major share of the revenues that are to be redistributed through this scheme. The $\ell$-households, on the other hand, are not compensated enough for the increase of congestion they experience ${ }^{32}$. This means that benefits and costs of recycling through this scheme are to some extent distributed in an inequitable way.

It is worth noting an additional result from Figure 3. High-income workers

\footnotetext{
${ }^{32}$ This could, of course, be different if instead of the same percentage-point reduction of the labor tax for both groups, the government uses differentiated labor-tax reductions to attain a Pareto-improving reform.
} 

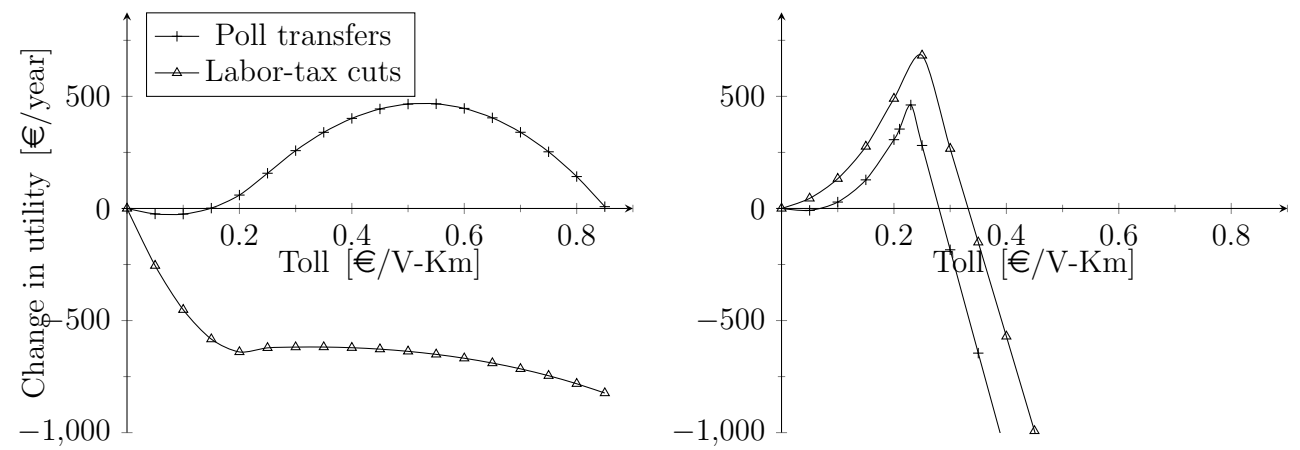

Figure 3: Change in utility for both recycling policies per type of household (base case)

get the maximum welfare gain at the point where low-income workers are tolled off $\operatorname{road} T$ (at $\tau=0.23$ for poll transfers and at $\tau=0.25$ for labor-tax cuts). Surprisingly, low-income workers also get the highest benefits when they are tolled off (of course, only in the case of poll transfers). In fact, in this case they do not pay for the toll but get the transfers from the high-income group. This would imply that product differentiation is beneficial, even for lower income groups, provided the right allocation of toll revenues is used.

This is consistent with Small and Yan (2001) in the sense that, there is a welfare gain when heterogeneity is accounted for. However, given that we consider labor markets, revenue allocation and redistribution ${ }^{33}$, we find that the efficiency gain and the impact on both types of users depend on the way toll revenues are spent.

Even if this result contrasts with that of Parry and Bento (2001), it seems to be in line with Proost and Van Regemorter (1995) who show that the choice of the recycling scheme depends on preexisting conditions in the labor market ${ }^{34}$.

\footnotetext{
${ }^{33}$ Small and Yan (2001) do not deal with the use of the toll revenues nor the effects of redistribution among users. Their focus is instead on the efficiency of the second-best one-route pricing policy compared with the first-best result.

${ }^{34}$ Proost and Van Regemorter (1995) use an AGE-model for Belgium to study the effects of a carbon-energy tax, by comparing the same two kinds of revenue recycling measures, but analyze a classical unemployment regime with sticky real wages and a well-functioning economy.
} 

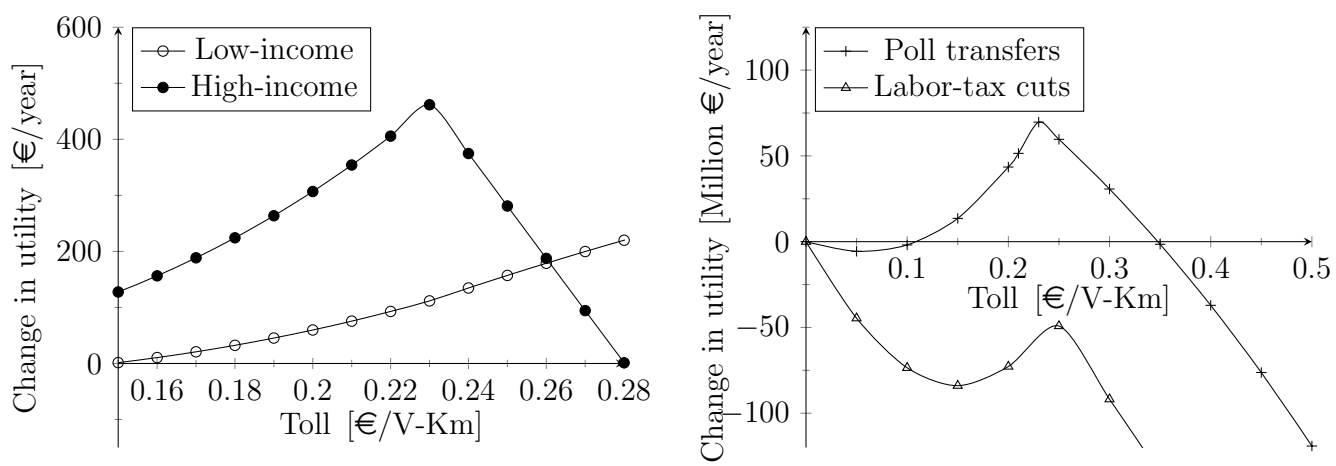

Figure 4: Welfare gains per household with poll-transfer recycling (left) and total welfare for both recycling policies (right)

Under the Pareto principle only recycling through poll transfers represents an improvement over the NTE. When acceptability requires the consent of both types of households, only this tax reform would be approved. Under this recycling regime, any toll level in the range from 0.15 to 0.28 would make all households better off (left panel Figure 4). The choice of the toll level depends on the government's distribution concerns. Toll values close to the separatingregime level (e.g. 0.23) favor the highly productive workers (without making the $\ell$-group worse off), and toll values closer to the higher limit (e.g. 0.28) favor the less productive workers (without making the $h$-group worse off). This implies that a toll level higher than the one that achieves efficiency in the transport market can be justified in regard to redistribution and acceptability concerns. Total welfare, obtained by the unweighted aggregation of utilities, is depicted in the right panel of Figure 4. Welfare effects of labor-tax recycling are negative whereas poll-transfer recycling can be considered as potentialPareto welfare improving in the range from 0.1 to $0.35 € / \mathrm{V}-\mathrm{Km}^{35}$.

\subsection{The importance of congestibility of the untolled alternative}

We explore here one of the key assumptions of our model: congestion on the untolled alternative. In this case, this road's congestion function is replaced by a constant time-per-unit-of-distance function. This means that,

\footnotetext{
${ }^{35}$ Note that the potential-Pareto set (Kaldor-Hicks criterion) contains the strict-Pareto subset identified in the left panel of Figure 4.
} 
independent of the travel speed, an extra trip added to this road does not increase the user's time cost. We call this a non-congestible alternative. We calibrate the time function to exhibit the same speed as road $T$ at the $N T E^{36}$ $(16 \mathrm{Km} / \mathrm{h})$. The rest of the parameters remain unchanged, except for $\alpha_{X}$ that, as in the base case, is chosen to imply on average 200 days of work per year at the NTE.
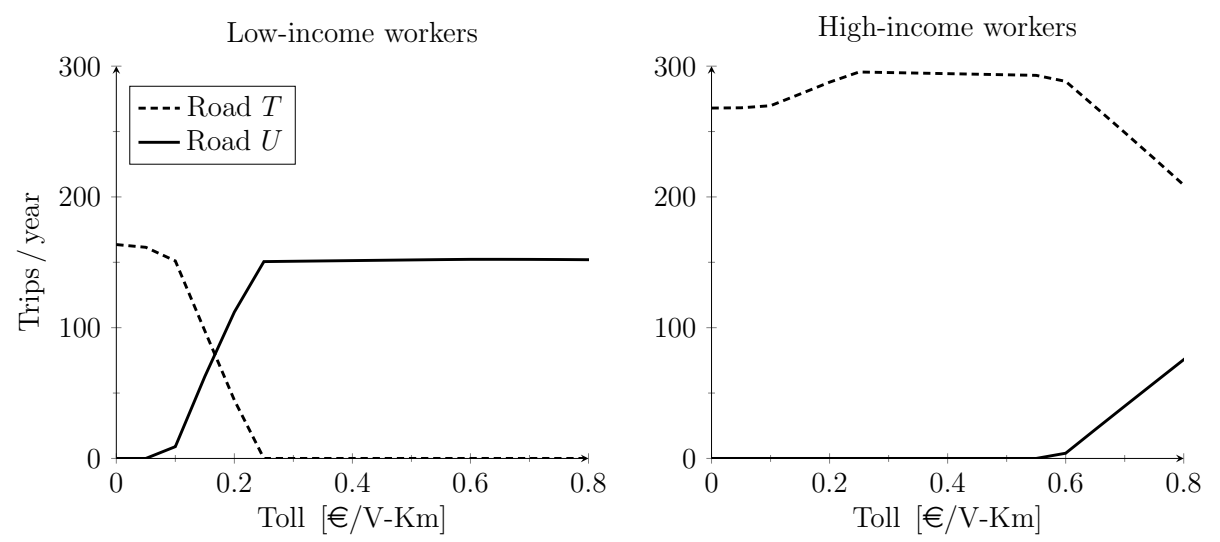

Figure 5: Trips per household with a non-congestible alternative (labor-tax recycling)

Travel patterns change significantly (Figure 5), not because the fixed-time cost of $U$, but rather because both roads exhibit a high time cost at the NTE. At this point, consumers only use road $T$. As the toll increases high-income households increase the use of this road and the low-income ones switch to $\operatorname{road} U$.

Not surprisingly, the negative impact on labor supply is reduced now that road $U$ can accommodate the traffic removed from $T$ without any congestion effect (Figure 6). When toll revenues are recycled through labor-tax cuts, the net impact on aggregate labor supply is positive (right panel Figure 6), as in Parry and Bento (2001). This means that neglecting congestion on the untolled alternative may result in an overestimation of the labor-supply gains from labor-tax recycling. On the other hand, if toll revenues are recycled via

\footnotetext{
${ }^{36}$ Think of this as a road with infinite capacity but whose travel speed is somehow limited to a given level. We take road $T$ speed as a reference in order to be coherent with the previous section.
} 

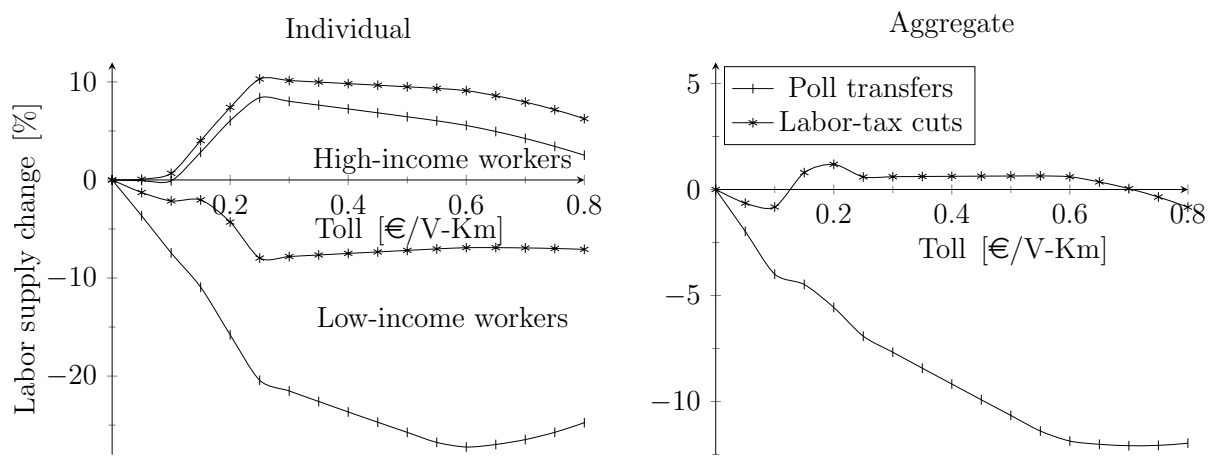

Figure 6: Labor supply with a non-congestible alternative: per type of household (left) and aggregate (right)

poll transfers, the effects on aggregate labor supply are still negative given the labor supply reduction by the less skilled.

Welfare effects of both policies are similar to those in Figure 3. Recycling through labor-tax cuts remains welfare reducing for the low-income group and welfare improving for the high-income group. A separating equilibrium is beneficial for both groups. The main difference with the base-case result is that eliminating congestion on the alternative road increases the potential welfare gains from each regime.The labor-tax recycling scheme becomes (potential-Pareto) welfare improving for a large range of toll levels (right panel Figure 7). These results are clearly driven by the assumptions on the substitute for the tolled road. As highlighted by Basso and Silva (2014), congestion pricing can be welfare improving for low-income groups if the substitute of the tolled infrastructure-in their case public transport-is optimized to accommodate the demand that is tolled off.

\subsection{The relative size of the income groups}

We briefly consider the sensitivity of results to the relative size of the income groups. Our results show that the composition of the economy plays an important role in the efficiency and welfare effects of the tolling policy.

We vary the size of the groups to imply a share for the low-income group of 5 to $95 \%$. We find that the higher the proportion of low-income households in the economy, the higher the reduction of congestion on road $T$. Clearly, the more commuters that are willing to leave the tolled road whenever a toll 

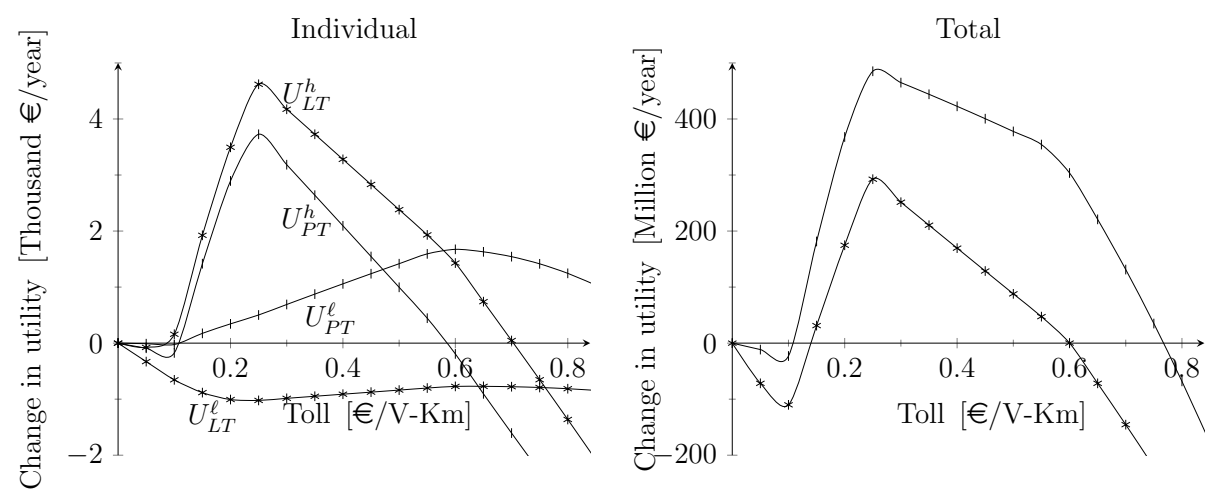

Figure 7: Change in utility for both recycling policies with a non-congestible alternative: per type of household (left) and total (right)

is imposed, the more traffic can be removed from $T$. The reduction of travel time ranges from around $4 \%$, when the share of the $\ell$-households is $5 \%$, to around $48 \%$, when the share of the $\ell$-households is $95 \%$. A higher share of the low-income group benefits therefore the high-income group in terms of congestion reduction.

Interestingly, the pattern of households that benefit from the tolling policy changes with the variation of these shares (Table 1). The tolling policy is beneficial for high-income commuters whenever the share of the $\ell$-group is higher than $45 \%$, regardless of the recycling scheme. This is because the group with the lowest value of time should represent more than a certain proportion of the population to obtain a significant reduction of congestion from a tolling policy. On the other hand, the $\ell$-group benefits only when its share is lower than $75 \%$ and toll revenues are recycled via poll transfers. Basically, if the majority of households are low-income, toll revenues (paid by those who keep using $T$ ) are not enough to compensate this group for being diverted from $T$.

Only one Pareto-improving policy was found (Table 1). This policy requires two conditions. First, toll revenues should be recycled via poll transfers (the recycling scheme that does not harm the $\ell$-group). Second, the share for the $\ell$-group should be in the range between $45 \%$ and $75 \%{ }^{37}$. This en-

\footnotetext{
${ }^{37}$ These ranges are for the set of parameters of the base case. Of course, changes of
} 
Table 1: Pattern of households that benefit from the tolling policy

\begin{tabular}{ccc}
\hline Policy & Share of the $\ell$-group & Who gains \\
\hline Poll transfers & $\ell<45 \%$ & Only $\ell$-group gains \\
Poll transfers & $45 \% \leq \ell \leq 75 \%$ & Both groups gain \\
Poll transfers & $\ell>75 \%$ & Only $h$-group gains \\
Labor-tax cuts & $\ell<45 \%$ & No gain \\
Labor-tax cuts & $\ell \geq 45 \%$ & Only $h$-group gains \\
\hline
\end{tabular}

sures that the reduction of congestion is attractive enough for the $h$-group $(\ell \geq 45 \%)$ and that the head transfer is enough to compensate the $\ell$-group for being diverted from $T(\ell \leq 75 \%)$.

The variation of the group shares also affects labor supply. This is directly related to the efficiency of the instrument in terms of reducing congestion. The higher the share of the low-income group, the more the high-income group will increase its labor supply and benefit from the pricing of one of the roads.

\section{Conclusion}

This paper considered the introduction of road pricing in an economy with low and high productivity workers and where only one of two congested links can be tolled. Revenues can be recycled via poll transfers or labortax cuts. We show that the introduction of a toll recycled via lower labor taxes may benefit only the more productive workers. The main reason is that the less productive workers, who are tolled off the fast route, end up on the more congested untolled route and are insufficiently compensated by the labor tax reduction. For this reason recycling via a head subsidy may make road pricing more acceptable. Of course, whenever the untolled route is not subject to congestion, road pricing becomes a much more efficient instrument and it is much more likely that labor tax recycling becomes an acceptable instrument.

Our results are relevant for all situations where the transport network

some of those parameters could shift the limits of the ranges, but that should not change the main insight. 
cannot be tolled completely and where there are large differences in worker productivity. In many developing and developed countries these two conditions are present. The untolled alternative can be back roads or public transport. Some countries (e.g. France) even require the presence of an untolled alternative for every road that is tolled. We show that this is not a guarantee for a Pareto-improvement.

This paper can be extended in several ways. One can consider more complex networks, consider explicitly two modes rather than two links, introduce other local externalities along the two roads, consider leisure trips in addition, etc. However, this is unlikely to change our main insights.

\section{Acknowledgements}

For useful comments we would like to thank the editor and two referees, as well as S. Tchung-Ming, F. Dunkerley, A. Ayong Le Kama, L. De Maack, and A. Decoster. We also thank participants of the ITEA Conference 2013 and the seminar FLM-CEC N${ }^{\circ} 61$. Financial support of IFP Energies Nouvelles and EIB, administered via the EIBURS Program, is gratefully acknowledged.

\section{Bibliography}

Baccani, B., Semecurbe, F., Thomas, G., 2007. Les deplacements domiciletravail amplifies par la periurbanisation. INSEE PREMIERE 1129, INSEE.

Basso, L. J., Silva, H. E., 2014. Efficiency and substitutability of transit subsidies and other urban transport policies. American Economic Journal: Economic Policy 6 (4), 1-33.

De Borger, B., 2009. Commuting, congestion tolls and the structure of the labour market: Optimal congestion pricing in a wage bargaining model. Regional Science and Urban Economics 39 (4), 434 - 448.

de Palma, A., Lindsey, R., 2004. Congestion pricing with heterogeneous travelers: A general-equilibrium welfare analysis. Networks and Spatial Economics 4 (2), 135-160.

E.C., 2009. Evolution of oil and petroleum product prices and taxation levels during the year 2008 in the european union. Tech. rep., Market Observatory for Energy. European Commission. 
Fesseau, M., Bellamy, V., Raynaud, E., 2009. Inequality between households in the national accounts. INSEE PREMIERE 1265A, INSEE.

Gutierrez-i Puigarnau, E., van Ommeren, J., 2009. Labour supply and commuting. Discussion paper, Tinbergen Institute.

Jara-Diaz, S. R., 2000. Allocation and valuation of travel time savings. Handbooks in Transport 1, 303-319.

Mayeres, I., Proost, S., 1997. Optimal tax and public investment rules for congestion type of externalities. Scandinavian Journal of Economics 99 (2), 261-79.

Mayeres, I., Proost, S., 2001. Can we use transport accounts for pricing policy and distributional analysis? Energy, Transport and Environment Working Papers Series ETE0123, Katholieke Universiteit Leuven, CES.

Parry, I. W. H., Bento, A., 2001. Revenue recycling and the welfare effects of road pricing. Scandinavian Journal of Economics 103 (4), 645-71.

Parry, I. W. H., Oates, W. E., 2000. Policy analysis in the presence of distorting taxes. Journal of Policy Analysis and Management 19, 603-613.

Parry, I. W. H., Small, K. A., 2005. Does Britain or the United States have the right gasoline tax? American Economic Review 95 (4), 1276-1289.

Proost, S., Van Regemorter, D., 1995. The double dividend and the role of inequality aversion and macroeconomic regimes. International Tax and Public Finance 2 (2), 207-219.

Rouwendal, J., Verhoef, E. T., 2004. Second-best pricing for imperfect substitutes in urban networks. Research in Transportation Economics 9 (1), $27-60$.

Small, K. A., Verhoef, E. T., 2007. The economics of urban transportation. Routledge.

Small, K. A., Yan, J., 2001. The value of "value pricing" of roads: Secondbest pricing and product differentiation. Journal of Urban Economics 49 (2), 310-336. 
Van Dender, K., 2003. Transport taxes with multiple trip purposes. Scandinavian Journal of Economics 105 (2), 295-310.

Verhoef, E. T., Small, K. A., 2004. Product differentiation on roads. Journal of Transport Economics and Policy (JTEP) 38 (1), 127-156.

\section{Appendix A. Notation}

$\begin{array}{ll}\text { Symbol } & \text { Meaning } \\ R=U, T & \text { Index type of road: } U \text { untolled road and } T \text { tolled road } \\ i=\ell, h & \text { Index type of household: } \ell \text { low-income and } h \text { high-income } \\ N & \text { Total number of households } \\ n^{i} & \text { Number of households } i \text {-type } \\ X^{i} & \text { Consumption of market goods } \\ t_{L}^{i} & \text { Leisure time } \\ D_{R}^{i} & \text { Number of commuting days } \\ G & \text { Head transfer } \\ F & \text { Public goods } \\ \mathcal{U}^{i}\left(X^{i}, t_{L}^{i}\right) & \text { Utility of consumption-leisure } \\ \Psi^{i}\left(D_{R}^{i}\right) & \text { Disutility of commuting } \\ t_{R}\left(n^{i}, D_{R}^{i}\right) & \text { Time per unit of distance } \\ \tau_{g} & \text { Fuel tax } \\ \tau_{w}^{i} & \text { Labor tax } \\ \tau & \text { Toll per unit of distance } \\ g & \text { Fuel price } \\ c_{g} & \text { Resource fuel cost } \\ d_{R} & \text { Distance } \\ \beta & \text { Distance difference between the roads }\left(\beta=d_{U} / d_{T}\right) \\ \varepsilon^{i} & \text { Labor productivity per day } \\ \omega & \text { Gross daily wage } \\ \bar{t} & \text { Household's time endowment in a period } \\ c_{R}^{i} & \text { Generalized cost of a trip } \\ \theta^{i} & \text { Social weight }\end{array}$




\section{Appendix B. The household's problem}

The household's problem defined by (1), (2) and (3) can be solved by maximizing the following Lagrangian function:

$$
\begin{gathered}
\mathcal{L}=\mathcal{U}\left(X, t_{L}\right)+\Psi\left(D_{U}, D_{T}\right)-\lambda_{c}\left[X+g d_{U} D_{U}+(g+\tau) d_{T} D_{T}\right. \\
\left.-\varepsilon w\left(1-\tau_{w}\right)\left(D_{U}+D_{T}\right)-G\right]+\mu_{c}\left[\bar{t}-D_{U}\left(1+t_{U} \beta d_{T}\right)-D_{T}\left(1+t_{T} d_{T}\right)-t_{L}\right],
\end{gathered}
$$

where the Lagrangian multiplier related to the income constraint $\left(\lambda_{c}\right)$ is the marginal utility of income, and the Lagrangian multiplier related to the time constraint $\left(\mu_{c}\right)$ is the resource value of time. For $X>0, D_{U}>0, D_{T}>0$ and $t_{L}>0$, the system of first-order conditions can be written as:

$$
\begin{aligned}
& \frac{\partial \mathcal{L}}{\partial X}=U_{X}-\lambda_{c}=0 \quad \Rightarrow \lambda_{c}=U_{X} \\
& \frac{\partial \mathcal{L}}{\partial t_{L}}=U_{t_{L}}-\mu_{c}=0 \quad \Rightarrow \mu_{c}=U_{t_{L}} \\
& \frac{\partial \mathcal{L}}{\partial D_{U}}=\Psi_{D_{U}}-\lambda_{c}\left[g \beta d_{T}-\varepsilon w\left(1-\tau_{w}\right)\right]-\mu_{c}\left(1+t_{U} \beta d_{T}\right)=0 \\
& \frac{\partial \mathcal{L}}{\partial D_{T}}=\Psi_{D_{T}}-\lambda_{c}\left[(g+\tau) d_{T}-\varepsilon w\left(1-\tau_{w}\right)\right]-\mu_{c}\left(1+t_{T} d_{T}\right)=0
\end{aligned}
$$

Using these conditions and both budget constraints, we obtain the demand functions for $X^{*}, D_{U}^{*}, D_{T}^{*}$, and $t_{L}^{*}$. Replacing these functions in the utility gives the indirect utility function $v\left(\tau_{g}, \tau_{w}, \tau, t_{T}, t_{U}, w, \varepsilon, G\right)$ which enables rewriting the household's problem as:

$$
\begin{gathered}
\mathcal{L}=v\left(\tau_{g}, \tau_{w}, \tau, t_{T}, t_{U}, w, \varepsilon, G\right)+\lambda_{c}\left[X+g d_{U} D_{U}+(g+\tau) d_{T} D_{T}\right. \\
\left.-\varepsilon w\left(1-\tau_{w}\right)\left(D_{U}+D_{T}\right)-G\right]-\mu_{c}\left[\bar{t}-D_{U}\left(1+t_{U} \beta d_{T}\right)-D_{T}\left(1+t_{T} d_{T}\right)-t_{L}\right] .
\end{gathered}
$$

F.O.C.:

$$
\begin{array}{ll}
\frac{\partial \mathcal{L}}{\partial \tau}=v_{\tau}+\lambda_{c} d_{T} D_{T}=0 & \Rightarrow v_{\tau}=-U_{X} d_{T} D_{T} \\
\frac{\partial \mathcal{L}}{\partial \tau_{g}}=v_{\tau_{g}}+\lambda_{c} c_{g} d_{T}\left(\beta D_{U}+D_{T}\right)=0 & \Rightarrow v_{\tau_{g}}=-U_{X} c_{g} d_{T}\left(\beta D_{U}+D_{T}\right) \\
\frac{\partial \mathcal{L}}{\partial \tau_{w}}=v_{\tau_{w}}+\lambda_{c} \varepsilon w\left(D_{U}+D_{T}\right)=0 & \Rightarrow v_{\tau_{w}}=-U_{X} \varepsilon w\left(D_{U}+D_{T}\right) \\
\frac{\partial \mathcal{L}}{\partial t_{U}}=v_{t_{U}}+\mu_{c} d_{U} D_{U}=0 & \Rightarrow v_{t_{U}}=-U_{t_{L}} d_{U} D_{U} \\
\frac{\partial \mathcal{L}}{\partial t_{T}}=v_{t_{T}}+\mu_{c} d_{T} D_{T}=0 & \Rightarrow v_{t_{T}}=-U_{t_{L}} d_{T} D_{T} \\
\frac{\partial \mathcal{L}}{\partial G}=v_{G}-\lambda_{c}=0 & \Rightarrow v_{G}=U_{X}
\end{array}
$$

Note that the marginal disutility of the toll increase $\left(v_{\tau}\right)$ is the marginal utility of income $\left(U_{X}\right)$ multiplied by the optimal number of trips $\left(D_{T}\right)$. Similarly, the marginal disutility of an increase of travel time on road $T\left(v_{t_{T}}\right)$ is the the resource value of time $\left(U_{t_{L}}\right)$ multiplied by the optimal number of trips. 


\section{Appendix C. User equilibrium conditions}

\begin{tabular}{c} 
Separating equilibrium \\
$\tau+g+t_{T}\left(n^{h} \boldsymbol{D}_{T}^{h}\right) \frac{U_{t_{L}}^{h}}{U_{X}^{h}}<\beta g+\beta t_{U}\left(n^{\ell} D_{U}^{\ell}\right) \frac{U_{t_{L}}^{h}}{U_{X}^{h}}$ \\
$\tau+g+t_{T}\left(n^{h} D_{T}^{h}\right) \frac{U_{t_{L}}^{\ell}}{U_{X}^{\ell}}>\beta g+\beta t_{U}\left(n^{\ell} \boldsymbol{D}_{U}^{\ell}\right) \frac{U_{t_{L}}^{\ell}}{U_{X}^{\ell}}$ \\
\hline
\end{tabular}

Partially separating equilibrium with the $\ell$-group separated

$$
\begin{gathered}
\tau+g+t_{T}\left(n^{h} \boldsymbol{D}_{\boldsymbol{T}}^{h}\right) \frac{U_{t_{L}}^{h}}{U_{X}^{h}}=\beta g+\beta t_{U}\left(n^{h} \boldsymbol{D}_{\boldsymbol{U}}^{h}+n^{\ell} D_{U}^{\ell}\right) \frac{U_{t_{L}}^{h}}{U_{X}^{h}} \\
\tau+g+t_{T}\left(n^{h} D_{T}^{h}\right) \frac{U_{t_{L}}^{\ell}}{U_{X}^{\ell}}>\beta g+\beta t_{U}\left(n^{h} D_{U}^{h}+n^{\ell} \boldsymbol{D}_{\boldsymbol{U}}^{\ell}\right) \frac{U_{t_{L}}^{\ell}}{U_{X}^{\ell}}
\end{gathered}
$$

Partially separating equilibrium with the h-group separated

$$
\begin{gathered}
\tau+g+t_{T}\left(n^{h} \boldsymbol{D}_{\boldsymbol{T}}^{h}+n^{\ell} D_{T}^{\ell}\right) \frac{U_{t_{L}}^{h}}{U_{X}^{h}}<\beta g+\beta t_{U}\left(n^{\ell} D_{U}^{\ell}\right) \frac{U_{t_{L}}^{h}}{U_{X}^{h}} \\
\tau+g+t_{T}\left(n^{h} D_{T}^{h}+n^{\ell} \boldsymbol{D}_{\boldsymbol{T}}^{\ell}\right) \frac{U_{t_{L}}^{\ell}}{U_{X}^{\ell}}=\beta g+\beta t_{U}\left(n^{\ell} \boldsymbol{D}_{\boldsymbol{U}}^{\ell}\right) \frac{U_{t_{L}}^{\ell}}{U_{X}^{\ell}}
\end{gathered}
$$

\section{Pooling equilibrium}

$$
\begin{aligned}
& \tau+g+t_{T}\left(n^{h} \boldsymbol{D}_{\boldsymbol{T}}^{h}+n^{\ell} D_{T}^{\ell}\right) \frac{U_{t_{L}}^{h}}{U_{X}^{h}}=\beta g+\beta t_{U}\left(n^{h} \boldsymbol{D}_{\boldsymbol{U}}^{h}+n^{\ell} D_{U}^{\ell}\right) \frac{U_{t_{L}}^{h}}{U_{X}^{h}} \\
& \tau+g+t_{T}\left(n^{h} D_{T}^{h}+n^{\ell} \boldsymbol{D}_{\boldsymbol{T}}^{\ell}\right) \frac{U_{t_{L}}^{\ell}}{U_{X}^{\ell}}=\beta g+\beta t_{U}\left(n^{h} D_{U}^{h}+n^{\ell} \boldsymbol{D}_{\boldsymbol{U}}^{\ell}\right) \frac{U_{t_{L}}^{\ell}}{U_{X}^{\ell}}
\end{aligned}
$$




\section{Appendix D. The social's planner problem}

\section{Appendix D.1. Separated equilibrium}

By assumption, in this case, $D_{U}^{h}=0$ and $D_{T}^{\ell}=0$.

Appendix D.1.1. Poll transfers

Differentiating the social welfare function with respect to $\tau$, when $d \tau$ affects $d G$, gives:

$$
\frac{d \mathbb{W}}{d \tau}=\theta^{h} n^{h}\left(v_{\tau}^{h}+v_{t_{T}}^{h} \frac{\partial t_{T}}{\partial D_{T}^{h}} \frac{d D_{T}^{h}}{d \tau}+v_{G}^{h} \frac{d G}{d \tau}\right)+\theta^{\ell} n^{\ell} v_{G}^{\ell} \frac{d G}{d \tau}
$$

with $\partial t_{T} / \partial D_{T}^{h}>0, d D_{T}^{h} / d \tau<0$, and $d G / d \tau>0$. Replacing B.2 into D.1 gives:

$$
\frac{d \mathbb{W}}{d \tau}=-\theta^{h} n^{h} d_{T} D_{T}^{h}\left(U_{X}^{h}+U_{t_{L}}^{h} \frac{\partial t_{T}}{\partial D_{T}^{h}} \frac{d D_{T}^{h}}{d \tau}\right)+\left(\theta^{h} n^{h} U_{X}^{h}+\theta^{\ell} n^{\ell} U_{X}^{\ell}\right) \frac{d G}{d \tau}
$$

Differentiating (10) with respect to $\tau$ gives the change in the transfer $(d G)$ associated to a change in the toll $(d \tau)$ :

$$
\frac{d G}{d \tau}=\frac{n^{h} d_{T}}{N}\left[\left(\tau+\tau_{g} c_{g}+\tau_{w} \frac{w \varepsilon^{h}}{d_{T}}\right) \frac{d D_{T}^{h}}{d \tau}+D_{T}^{h}\right]
$$

Inserting D.3 into D.2 and dividing by $U_{X}^{h}$, we have:

$$
\begin{aligned}
\frac{d \mathbb{W} / d \tau}{U_{X}^{h}} & =\left(\frac{\theta^{h} n^{h}}{N}+\frac{\theta^{\ell} n^{\ell}}{N} \frac{U_{X}^{\ell}}{U_{X}^{h}}\right)\left(\tau+\tau_{g} c_{g}+\tau_{w} \frac{w \varepsilon^{h}}{d_{T}}\right) \frac{d D_{T}^{h}}{d \tau} \\
& +\left(\frac{\theta^{h} n^{h}}{N}+\frac{\theta^{\ell} n^{\ell}}{N} \frac{U_{X}^{\ell}}{U_{X}^{h}}-\theta^{h}\right) D_{T}^{h}-\theta^{h} \frac{U_{t_{L}}^{h}}{U_{X}^{h}} D_{T}^{h} \frac{\partial t_{T}}{\partial D_{T}^{h}} \frac{d D_{T}^{h}}{d \tau}
\end{aligned}
$$

Setting $\frac{d \mathbb{W} / d \tau}{U_{X}^{h}}=0$, and defining the elasticity of demand of high-income consumers for the tolled road as $\epsilon_{D_{T}^{h}}^{\tau}=\frac{d D_{T}^{h}}{d \tau} \frac{\tau}{D_{T}^{h}}$, we get (11).

Appendix D.1.2. Labor-tax cuts

The welfare impact when incremental toll revenues are used to cut the labor-tax is:

$$
\frac{d \mathbb{W}}{d \tau}=\theta^{h} n^{h}\left(v_{\tau}^{h}+v_{t_{T}}^{h} \frac{\partial t_{T}}{\partial D_{T}^{h}} \frac{d D_{T}^{h}}{d \tau}+v_{\tau_{w}}^{h} \frac{d \tau_{w}}{d \tau}\right)+\theta^{\ell} n^{\ell} v_{\tau_{w}}^{\ell} \frac{d \tau_{w}}{d \tau}
$$

with $\frac{d \tau_{w}}{d \tau}<0$. Replacing B.2 into D.5 we have:

$$
\begin{aligned}
\frac{d \mathbb{W}}{d \tau}= & -\theta^{h} n^{h} d_{T} D_{T}^{h}\left(U_{X}^{h}+U_{t_{L}}^{h} \frac{\partial t_{T}}{\partial D_{T}^{h}} \frac{d D_{T}^{h}}{d \tau}\right) \\
& -\left(\theta^{h} n^{h} \varepsilon^{h} D_{T}^{h} U_{X}^{h}+\theta^{\ell} n^{\ell} \varepsilon^{\ell} D_{U}^{\ell} U_{X}^{\ell}\right) w \frac{d \tau_{w}}{d \tau}
\end{aligned}
$$

Differentiating (10) with respect to $\tau$ and solving for $w \frac{d \tau_{w}}{d \tau}$ gives:

$$
w \frac{d \tau_{w}}{d \tau}=\frac{-n^{h} d_{T}}{n^{h} \varepsilon^{h} D_{T}^{h}+n^{\ell} \varepsilon^{\ell} D_{U}^{\ell}}\left[\left(\tau+\tau_{g} c_{g}+\tau_{w} \frac{w \varepsilon^{h}}{d_{T}}\right) \frac{d D_{T}^{h}}{d \tau}+D_{T}^{h}\right]
$$

Inserting D.7 into D.6, dividing by $U_{X}^{h}$, setting $\frac{d \mathbb{W} / d \tau}{U_{X}^{h}}=0$, and using $\epsilon_{D_{T}^{h}}^{\tau}$ we get (12). 
Appendix D.2. Partially separated equilibrium with the $\ell$-group separated Here by assumption $D_{T}^{\ell}=0$.

\section{Appendix D.2.1. Poll transfers}

$$
\frac{d \mathbb{W}}{d \tau}=\theta^{h} n^{h}\left(v_{\tau}^{h}+v_{t_{T}}^{h} \frac{\partial t_{T}}{\partial D_{T}^{h}} \frac{d D_{T}^{h}}{d \tau}+v_{t_{U}}^{h} \frac{\partial t_{U}}{\partial D_{U}^{h}} \frac{\partial D_{U}^{h}}{\partial D_{T}^{h}} \frac{d D_{U}^{h}}{d \tau}+v_{G}^{h} \frac{d G}{d \tau}\right)+\theta^{\ell} n^{\ell} v_{G}^{\ell} \frac{d G}{d \tau}
$$

with $\frac{\partial D_{U}^{h}}{\partial D_{T}^{h}}<0$. Replacing B.2 into D.8 gives:

$$
\begin{aligned}
\frac{d \mathbb{W}}{d \tau}=-\theta^{h} n^{h} & \left(U_{X}^{h} d_{T} D_{T}^{h}+U_{t_{L}}^{h} d_{T} D_{T}^{h} \frac{\partial t_{T}}{\partial D_{T}^{h}} \frac{d D_{T}^{h}}{d \tau}+U_{t_{L}}^{h} \beta d_{T} D_{U}^{h} \frac{\partial t_{U}}{\partial D_{U}^{h}} \frac{\partial D_{U}^{h}}{\partial D_{T}^{h}} \frac{d D_{T}^{h}}{d \tau}\right. \\
& \left.-U_{X}^{h} \frac{d G}{d \tau}\right)+\theta^{\ell} n^{\ell} U_{G}^{\ell} \frac{d G}{d \tau}
\end{aligned}
$$

Differentiating (13) with respect to $\tau$ and solving for $\frac{d G}{d \tau}$ gives:

$$
\frac{d G}{d \tau}=\frac{n^{h} d_{T}}{N}\left[\left(\tau+\tau_{g} c_{g}\left(1+\beta \frac{\partial D_{U}^{h}}{\partial D_{T}^{h}}\right)+\tau_{w} \frac{w \varepsilon^{h}}{d_{T}}\left(1+\frac{\partial D_{U}^{h}}{\partial D_{T}^{h}}\right)\right) \frac{d D_{T}^{h}}{d \tau}+D_{T}^{h}\right]
$$

Inserting D.10 into D.9, dividing by $U_{X}^{h}$, setting $\frac{d \mathbb{W} / d \tau}{U_{X}^{h}}=0$, and using $\epsilon_{D_{T}^{h}}^{\tau}$ we get (14).

Appendix D.2.2. Labor-tax cuts

$$
\frac{d \mathbb{W}}{d \tau}=\theta^{h} n^{h}\left(v_{\tau}^{h}+v_{t_{T}}^{h} \frac{\partial t_{T}}{\partial D_{T}^{h}} \frac{d D_{T}^{h}}{d \tau}+v_{t_{U}}^{h} \frac{\partial t_{U}}{\partial D_{U}^{h}} \frac{\partial D_{U}^{h}}{\partial D_{T}^{h}} \frac{d D_{U}^{h}}{d \tau}+v_{\tau_{w}}^{h} \frac{d \tau_{w}}{d \tau}\right)+\theta^{\ell} n^{\ell} v_{\tau_{w}}^{\ell} \frac{d \tau_{w}}{d \tau}
$$

Replacing B.2 into D.11 gives:

$$
\begin{aligned}
\frac{d \mathbb{W}}{d \tau}=-\theta^{h} n^{h} & \left(U_{X}^{h} d_{T} D_{T}^{h}+U_{t_{L}}^{h} d_{T} D_{T}^{h} \frac{\partial t_{T}}{\partial D_{T}^{h}} \frac{d D_{T}^{h}}{d \tau}+U_{t_{L}}^{h} \beta d_{T} D_{U}^{h} \frac{\partial t_{U}}{\partial D_{U}^{h}} \frac{\partial D_{U}^{h}}{\partial D_{T}^{h}} \frac{d D_{T}^{h}}{d \tau}\right. \\
& \left.-U_{X}^{h} \varepsilon^{h} W\left(D_{T}^{h}+D_{U}^{h}\right) \frac{d \tau_{w}}{d \tau}\right)-\theta^{\ell} n^{\ell} U_{X}^{\ell} w \varepsilon^{\ell} D_{U}^{\ell} \frac{d \tau_{w}}{d \tau}
\end{aligned}
$$

Differentiating (13) with respect to $\tau$ and solving for $W \frac{d \tau_{w}}{d \tau}$ gives:

$$
\begin{aligned}
w \frac{d \tau_{w}}{d \tau}=-\frac{n^{h} d_{T}}{n^{h} \varepsilon^{h}\left(D_{T}^{h}+D_{U}^{h}\right)+n^{\ell} \varepsilon^{\ell} D_{U}^{\ell}} & {\left[\left(\tau+\tau_{g} c_{g}\left(1+\beta \frac{\partial D_{U}^{h}}{\partial D_{T}^{h}}\right)\right.\right.} \\
& \left.\left.+\tau_{w} \frac{w \varepsilon^{h}}{d_{T}}\left(1+\frac{\partial D_{U}^{h}}{\partial D_{T}^{h}}\right)\right) \frac{d D_{T}^{h}}{d \tau}+D_{T}^{h}\right]
\end{aligned}
$$

Inserting D.13 into D.12, dividing by $U_{X}^{h}$, setting $\frac{d \mathbb{W} / d \tau}{U_{X}^{h}}=0$, and using $\epsilon_{D_{T}^{h}}^{\tau}$ we get (15). 
Appendix D.3. Partially separated equilibrium with the h-group separated and revenues recycled via poll transfers

Here by assumption $D_{U}^{h}=0$.

$$
\begin{aligned}
\frac{d \mathbb{W}}{d \tau}=\theta^{h} n^{h} & \left(v_{\tau}^{h}+v_{t_{T}}^{h} \frac{\partial t_{T}}{\partial D_{T}^{h}} \frac{d D_{T}^{h}}{d \tau}+v_{G}^{h} \frac{d G}{d \tau}\right)+\theta^{\ell} n^{\ell}\left(v_{\tau}^{\ell}+v_{t_{T}}^{\ell} \frac{\partial t_{T}}{\partial D_{T}^{\ell}} \frac{d D_{T}^{\ell}}{d \tau}\right. \\
& \left.+v_{t_{U}}^{\ell} \frac{\partial t_{U}}{\partial D_{U}^{\ell}} \frac{\partial D_{U}^{\ell}}{\partial D_{T}^{\ell}} \frac{d D_{T}^{\ell}}{d \tau}+v_{G}^{\ell} \frac{d G}{d \tau}\right)
\end{aligned}
$$

Replacing B.2 into D.14 gives:

$$
\begin{aligned}
\frac{d \mathbb{W}}{d \tau}= & -\left(\theta^{h} n^{h} U_{X}^{h} D_{T}^{h}+\theta^{\ell} n^{\ell} U_{X}^{\ell} D_{T}^{\ell}\right) d_{T}-\left(\theta^{h} n^{h} U_{t_{L}}^{h} D_{T}^{h} \frac{\partial t_{T}}{\partial D_{T}^{h}} \frac{d D_{T}^{h}}{d \tau}+\theta^{\ell} n^{\ell} U_{t_{L}}^{\ell} D_{T}^{\ell} \frac{\partial t_{T}}{\partial D_{T}^{\ell}} \frac{d D_{T}^{\ell}}{d \tau}\right) d_{T} \\
& -\theta^{\ell} n^{\ell} U_{t_{L}}^{\ell} \beta d_{T} D_{U}^{\ell} \frac{\partial t_{U}}{\partial D_{U}^{\ell}} \frac{\partial D_{U}^{\ell}}{\partial D_{T}^{\ell}} \frac{d D_{T}^{\ell}}{d \tau}+\left(\theta^{h} n^{h} U_{X}^{h}+\theta^{\ell} n^{\ell} U_{X}^{\ell}\right) \frac{d G}{d \tau}
\end{aligned}
$$

Differentiating (16) with respect to $\tau$ and solving for $\frac{d G}{d \tau}$ gives:

$$
\begin{aligned}
\frac{d G}{d \tau}=\frac{d_{T}}{N}[ & \tau\left(n^{h} \frac{d D_{T}^{h}}{d \tau}+n^{\ell} \frac{d D_{T}^{\ell}}{d \tau}\right)+\tau_{g} c_{g}\left(n^{h} \frac{d D_{T}^{h}}{d \tau}+n^{\ell}\left(1+\beta \frac{\partial D_{U}^{\ell}}{\partial D_{T}^{\ell}}\right) \frac{d D_{T}^{\ell}}{d \tau}\right) \\
& \left.+\tau_{w} \frac{w}{d_{T}}\left(n^{h} \varepsilon^{h} \frac{d D_{T}^{h}}{d \tau}+n^{h} \varepsilon^{h}\left(1+\frac{\partial D_{U}^{\ell}}{\partial D_{T}^{\ell}}\right) \frac{d D_{T}^{\ell}}{d \tau}\right)+n^{h} D_{T}^{h}+n^{\ell} D_{T}^{\ell}\right]
\end{aligned}
$$

Inserting D.16 into D.15, dividing by $U_{X}^{h}$, setting $\frac{d \mathbb{W} / d \tau}{U_{X}^{h}}=0$, and using $\epsilon_{D_{T}^{i}}^{\tau}$ we get (17).

Appendix D.4. Pooling equilibrium and revenues recycled via poll transfers

In this equilibrium both kinds of households take both roads. Assume that if the toll increases, both groups reduce the number of trips they make by road $T$ and increase the number of trips they make by road $U$. Also assume that road users reduce the number of trips on $T$ only as a result of the toll increase. These assumptions were relaxed in the numerical illustration. The government's budget constraint is:

$$
\begin{aligned}
w \tau_{w}\left(n ^ { h } \varepsilon ^ { h } \left(D_{T}^{h}\right.\right. & \left.\left.+D_{U}^{h}\right)+n^{\ell} \varepsilon^{\ell}\left(D_{T}^{\ell}+D_{U}^{\ell}\right)\right)+\tau_{g} c_{g} d_{T}\left(n^{h}\left(D_{T}^{h}+\beta D_{U}^{h}\right)\right. \\
& \left.+n^{\ell}\left(D_{T}^{\ell}+\beta D_{U}^{\ell}\right)\right)+\tau d_{T}\left(n^{h} D_{T}^{h}+n^{\ell} D_{T}^{\ell}\right)=F+N G .
\end{aligned}
$$

Differentiating the social welfare function with respect to $\tau$, when $d \tau$ affects $d G$, gives:

$$
\begin{aligned}
\frac{d \mathbb{W}}{d \tau} & =\theta^{h} n^{h}\left(v_{\tau}^{h}+v_{t_{T}}^{h} \frac{\partial t_{T}}{\partial D_{T}^{h}} \frac{d D_{T}^{h}}{d \tau}+v_{t_{U}}^{h} \frac{\partial t_{U}}{\partial D_{U}^{h}} \frac{\partial D_{U}^{h}}{\partial D_{T}^{h}} \frac{d D_{T}^{h}}{d \tau}+v_{G}^{h} \frac{d G}{d \tau}\right) \\
& +\theta^{\ell} n^{\ell}\left(v_{\tau}^{\ell}+v_{t_{T}}^{\ell} \frac{\partial t_{T}}{\partial D_{T}^{\ell}} \frac{d D_{T}^{\ell}}{d \tau}+v_{t_{U}}^{\ell} \frac{\partial t_{U}}{\partial D_{U}^{\ell}} \frac{\partial D_{U}^{\ell}}{\partial D_{T}^{\ell}} \frac{d D_{T}^{\ell}}{d \tau}+v_{G}^{\ell} \frac{d G}{d \tau}\right)
\end{aligned}
$$


Replacing B.2 into D.18 gives:

$$
\begin{aligned}
& \frac{d \mathbb{W}}{d \tau}=-\left(\theta^{h} n^{h} U_{X}^{h} D_{T}^{h}+\theta^{\ell} n^{\ell} U_{X}^{\ell} D_{T}^{\ell}\right) d_{T}-\left(\theta^{h} n^{h} U_{t_{L}}^{h} D_{T}^{h} \frac{\partial t_{T}}{\partial D_{T}^{h}} \frac{d D_{T}^{h}}{d \tau}+\theta^{\ell} n^{\ell} U_{t_{L}}^{\ell} D_{T}^{\ell} \frac{\partial t_{T}}{\partial D_{T}^{\ell}} \frac{d D_{T}^{\ell}}{d \tau}\right) d_{T} \\
& -\left(\theta^{h} n^{h} U_{t_{L}}^{h} D_{U}^{h} \frac{\partial t_{U}}{\partial D_{U}^{h}} \frac{\partial D_{U}^{h}}{\partial D_{T}^{h}} \frac{d D_{T}^{h}}{d \tau}+\theta^{\ell} n^{\ell} U_{t_{L}}^{\ell} D_{U}^{\ell} \frac{\partial t_{U}}{\partial D_{U}^{\ell}} \frac{\partial D_{U}^{\ell}}{\partial D_{T}^{\ell}} \frac{d D_{T}^{\ell}}{d \tau}\right) \beta d_{T}+\left(\theta^{h} n^{h} U_{X}^{h}+\theta^{\ell} n^{\ell} U_{X}^{\ell}\right) \frac{d G}{d \tau}
\end{aligned}
$$

Differentiating (D.17) with respect to $\tau$ and solving for $\frac{d G}{d \tau}$ gives:

$$
\begin{aligned}
\frac{d G}{d \tau}=\frac{d_{T}}{N}\left[\tau\left(n^{h} \frac{d D_{T}^{h}}{d \tau}+n^{\ell} \frac{d D_{T}^{\ell}}{d \tau}\right)+\tau_{g} c_{g}\left(n^{h}\left(1+\beta \frac{\partial D_{U}^{h}}{\partial D_{T}^{h}}\right) \frac{d D_{T}^{h}}{d \tau}+n^{\ell}\left(1+\beta \frac{\partial D_{U}^{\ell}}{\partial D_{T}^{\ell}}\right) \frac{d D_{T}^{\ell}}{d \tau}\right)\right. \\
\left.+\tau_{w} \frac{w}{d_{T}}\left(n^{h} \varepsilon^{h}\left(1+\frac{\partial D_{U}^{h}}{\partial D_{T}^{h}}\right) \frac{d D_{T}^{h}}{d \tau}+n^{h} \varepsilon^{h}\left(1+\frac{\partial D_{U}^{\ell}}{\partial D_{T}^{\ell}}\right) \frac{d D_{T}^{\ell}}{d \tau}\right)+n^{h} D_{T}^{h}+n^{\ell} D_{T}^{\ell}\right]
\end{aligned}
$$

Inserting D.20 into D.19, dividing by $U_{X}^{h}$, setting $\frac{d \mathbb{W} / d \tau}{U_{X}^{h}}=0$, and using $\epsilon_{D_{T}^{i}}^{\tau}$ we get:

$$
\begin{aligned}
\tau_{p t}=\frac{1}{1-\phi_{p t} \vartheta-\zeta}[ & E_{D_{T}^{h}}^{\tau} \frac{U_{t_{L}}^{h}}{U_{X}^{h}}\left(\frac{\partial t_{T}}{\partial D_{T}^{h}} D_{T}^{h}+\frac{\partial t_{U}}{\partial D_{U}^{h}} D_{U}^{h} \beta D_{T U}^{h}\right) \\
& \left.+\frac{\theta^{\ell}}{\theta^{h}} E_{D_{T}^{\ell}}^{\tau} \frac{U_{t_{L}}^{\ell}}{U_{X}^{h}}\left(\frac{\partial t_{T}}{\partial D_{T}^{\ell}} D_{T}^{\ell}+\frac{\partial t_{U}}{\partial D_{U}^{\ell}} D_{U}^{\ell} \beta D_{T U}^{\ell}\right)\right] \\
-\frac{1-\phi_{p t} \vartheta}{1-\phi_{p t} \vartheta-\zeta}[ & \tau_{g} c_{g}\left(E_{D_{T}^{h}}^{\tau}\left(1+\beta D_{T U}^{h}\right)+E_{D_{T}^{\ell}}^{\tau}\left(1+\beta D_{T U}^{\ell}\right)\right) \\
& \left.+\tau_{w} \frac{w}{d_{T}}\left(E_{D_{T}^{h}}^{\tau} \varepsilon^{h}\left(1+D_{T U}^{h}\right)+E_{D_{T}^{\ell}}^{\tau} \varepsilon^{\ell}\left(1+D_{T U}^{\ell}\right)\right)\right],
\end{aligned}
$$

This is the more general equation derived in this analysis. Interpretation is as explained in Section 4. 